\title{
A prototype method for diagnosing high ice water content probability using satellite imager data
}

\author{
Christopher R. Yost $^{1}$, Kristopher M. Bedka ${ }^{2}$, Patrick Minnis ${ }^{1}$, Louis Nguyen ${ }^{2}$, J. Walter Strapp ${ }^{3}$, \\ Rabindra Palikonda ${ }^{1}$, Konstantin Khlopenkov ${ }^{1}$, Douglas Spangenberg ${ }^{1}$, William L. Smith $\mathrm{Jr}^{2}{ }^{2}$, Alain Protat ${ }^{4}$, and \\ Julien Delanoe ${ }^{5}$ \\ ${ }^{1}$ Science Systems and Applications, Inc., Hampton, VA 23666, USA \\ ${ }^{2}$ NASA Langley Research Center, Hampton, VA 23681, USA \\ ${ }^{3}$ Met Analytics Inc., Aurora, Ontario, Canada \\ ${ }^{4}$ Australian Bureau of Meteorology, Melbourne, Australia \\ ${ }^{5}$ Laboratoire Atmosphere, Milieux, et Observations Spatiales, Guyancourt, France
}

Correspondence: Kristopher M. Bedka (kristopher.m.bedka@nasa.gov)

Received: 6 October 2017 - Discussion started: 1 November 2017

Revised: 6 February 2018 - Accepted: 13 February 2018 - Published: 22 March 2018

\begin{abstract}
Recent studies have found that ingestion of high mass concentrations of ice particles in regions of deep convective storms, with radar reflectivity considered safe for aircraft penetration, can adversely impact aircraft engine performance. Previous aviation industry studies have used the term high ice water content (HIWC) to define such conditions. Three airborne field campaigns were conducted in 2014 and 2015 to better understand how HIWC is distributed in deep convection, both as a function of altitude and proximity to convective updraft regions, and to facilitate development of new methods for detecting HIWC conditions, in addition to many other research and regulatory goals. This paper describes a prototype method for detecting HIWC conditions using geostationary (GEO) satellite imager data coupled with in situ total water content (TWC) observations collected during the flight campaigns. Three satellite-derived parameters were determined to be most useful for determining HIWC probability: (1) the horizontal proximity of the aircraft to the nearest overshooting convective updraft or textured anvil cloud, (2) tropopause-relative infrared brightness temperature, and (3) daytime-only cloud optical depth. Statistical fits between collocated TWC and GEO satellite parameters were used to determine the membership functions for the fuzzy logic derivation of HIWC probability. The products were demonstrated using data from several campaign flights and validated using a subset of the satellite-aircraft collocation database. The daytime HIWC probability was
\end{abstract}

found to agree quite well with TWC time trends and identified extreme TWC events with high probability. Discrimination of HIWC was more challenging at night with IRonly information. The products show the greatest capability for discriminating TWC $\geq 0.5 \mathrm{~g} \mathrm{~m}^{-3}$. Product validation remains challenging due to vertical TWC uncertainties and the typically coarse spatio-temporal resolution of the GEO data.

\section{Introduction}

Recent studies have documented many events since the early 1990s where aircraft flight through deep convective storms and cirrus anvil outflow has resulted in jet engine power loss, loss of engine control, and/or engine damage events (Lawson et al., 1998; Mason et al., 2006; Bravin et al., 2015). Mason et al. (2006) reported that engine events occurred in seemingly innocuous cloud regions with only light to moderate turbulence, infrequent lightning, and where the pilot's radar indicated green or weaker echoes (< approximately $30 \mathrm{dBZ}$ ). This lead to their hypothesis that the aircraft were encountering high mass concentrations of small ice particles associated with convective updrafts, and ice accretion in the engine by ingested ice particles was likely the cause of the events. These encounters of high mass concentrations in low radar reflectivity have been termed high ice water content (HIWC) events. 
Subsequent meteorological analyses support that HIWC can be found within or near convective updrafts with a high concentration of small ice particles that would not produce a strong radar reflectivity (Platt et al., 2011; Gayet et al., 2012). Confirmation of many of the original hypotheses of Mason et al. (2006) was obtained in an exploratory in situ flight campaign in HIWC conditions (Grandin et al., 2014). In more recent years, icing of aircraft air data probes (e.g., pitot airspeed indicators) has also been recognized to occur in the same type of cloud conditions (Duvivier, 2010). The microphysical characteristics of HIWC events make this hazard difficult to identify and avoid based on currently available cloud information in the cockpit from weather radar.

There is currently no formal definition of HIWC, and levels and exposure distances required for ice accretion in engines have not yet been established. Individual industry researchers have typically chosen between 1 and $2 \mathrm{~g} \mathrm{~m}^{-3}$ as their HIWC thresholds, while accepting that $0.5 \mathrm{~g} \mathrm{~m}^{-3}$ does not appear to represent a threat. Here we choose a HIWC threshold of $1 \mathrm{~g} \mathrm{~m}^{-3}$, in the belief that, pending more information from ice accretion researchers on the threat levels, a more conservative definition is prudent for a detection scheme.

Geostationary (GEO) satellite observations and derived products have been used to analyze past HIWC events and could potentially be used to develop HIWC detection products, assuming that HIWC events occur in a consistent set of conditions. Through analysis of GEO data from historical inservice engine icing events over Japan and Southeast Asia experienced by Boeing aircraft, Bravin et al. (2015) found that these events occurred predominantly in mesoscale convective systems with relatively large anvils. The aircraft typically traversed through a long section (196 km on average) of cloud at or near the convective equilibrium level, also known as the level of neutral buoyancy, but also quite close $(41 \mathrm{~km}$ on average) to the center of a local area with cloud tops at least $10 \mathrm{~K}$ colder than the equilibrium level. These anomalously cold clouds often occur within or near "overshooting cloud tops" (OTs) which indicate small updraft cores $(<20 \mathrm{~km}$ diameter) of sufficient strength to penetrate through the anvil, typically located near to the equilibrium level. A $10 \mathrm{~K}$ temperature differential equates to more than a $2 \mathrm{~km}$ penetration of cloud top above anvil based on analysis of GEO imagery coincident with NASA CloudSat OT overpasses (Griffin et al., 2016). Bravin et al. (2015) showed that not only were the events close in location to such an OT, but also typically within an hour of the time of its maximum intensity, and not necessarily correlated to the time of the overall storm peak intensity.

One HIWC nowcasting approach has recently been published which seeks to maximize the HIWC event detection rate by identifying any ice cloud with moderate to high cloud optical depth (COD > 20, de Laat et al., 2017). Their approach seeks to combine satellite-derived cloud parameters to identify regions where total water content (TWC) could exceed $1 \mathrm{~g} \mathrm{~m}^{-3}$ anywhere throughout the vertical depth of a cloud. Their binary yes/no HIWC mask indicates where HIWC is possible, but does not provide information on where HIWC is likely, especially in deep convection where COD routinely exceeds 20 (Hong et al., 2007). Such an approach could identify a variety of cloud conditions where HIWC may be present, not necessarily restricted to the types of deep convection documented in Bravin et al. (2015).

The European High Altitude Ice Crystal (HAIC) and North American High Ice Water Content (HIWC) projects (Dezitter et al., 2013; Strapp et al., 2016a) have conducted several flight campaigns in recent years to collect in situ and remote sensing observations of ice water content within deep convective clouds at various temperature levels ranging from -10 to $-50^{\circ} \mathrm{C}$, a temperature range encompassing the typical ambient icing environment for aircraft climb, descent, and cruise. The overarching goal of these campaigns is to better characterize the atmospheric environment that causes engine and air data probe failures that threaten aviation safety. The campaigns seek to (1) help assess a new aircraft mixedphase/glaciated icing certification envelope (Mazzawy and Strapp, 2007) contained in FAA Title 14 Code of Federal Regulations Part 33 Appendix D that recently became law, by collecting in situ characterization measurements for comparison; (2) develop techniques for the aviation industry to detect and nowcast HIWC conditions for exit and avoidance; (3) provide data for specialized aviation applications such as engine modeling, ground cloud simulation facilities, and the development of certification means of compliance; and (4) take advantage of the unique data sets the campaigns will provide to support scientific research in the characterization of deep convection, fundamental cloud microphysics, cloud modeling, and the development of radar and satellite cloud remote sensing products.

The primary goals of the HAIC and HIWC campaigns were to provide statistics on the 99th percentile of in situ total water content (TWC), and characterize other relevant cloud parameters such as ice particle size for regulatory purposes. The high-frequency in situ TWC observations collected within the HAIC and HIWC campaigns are invaluable for development of satellite-based HIWC diagnostic products. Prior to these campaigns, a large sample of consistent in situ TWC data across diverse geographic regions had been lacking, which had prohibited HIWC diagnostic product development. GEO satellite imagers such as the Multifunction Transport Satellite (MTSAT) Japanese Meteorological Imager (JAMI), Geostationary Operational Environmental Satellite (GOES), and Meteosat Second Generation Spinning Enhanced Visible and Infrared Imager (SEVIRI) observed deep convective clouds throughout their lifecycles in 5 to 30 min intervals during the HAIC and HIWC campaigns, depending on the geographic region. GOES-14 observations were also collected at up to 1 min intervals on two flight days during a Super Rapid Scan Operations for GOESR (SRSOR, Schmit et al., 2014) period. GEO imager ob- 
servations and associated derived products depict storm intensity, locations of intense updrafts, and cloud-top microphysical characteristics that have previously been analyzed for a small sample of HIWC events. A more comprehensive analysis of GEO imagery relative to aircraft TWC measurements enables the research community to better understand the characteristics and evolution of clouds that do and do not produce HIWC. This understanding is critical for the development of satellite-based HIWC detection products.

This paper has two primary objectives, (1) to provide statistical analyses of cloud properties derived from GEO observations as a function of TWC using data from three recent flight campaigns and (2) to develop and demonstrate a prototype satellite-based probability of HIWC (PHIWC) diagnostic product. The three campaigns analyzed in this paper were the two HAIC-HIWC campaigns centered in Darwin, Australia in January-March 2014 and Cayenne, French Guiana in May 2015, and the NASA HIWC-RADAR campaign centered in Fort Lauderdale, Florida, in August 2015. The prototype algorithm developed here provides a more precise method for near-real time avoidance of HIWC conditions than previously available.

\section{Datasets}

\subsection{Experiment and flight campaign descriptions}

In 2006, an industry working group tasked by the FAA to review issues related to mixed-phase and glaciated icing conditions recommended the collection of a new in situ data set to characterize the microphysical properties of deep convective clouds, the type that had been identified as causing engine events. The HIWC Study was then initiated within North America and initially worked on the modification and development of new instrumentation required to make accurate measurements in hostile convective conditions, while plans for a flight campaign were developed.

In 2012, the HIWC team partnered with the HAIC Project to conduct the first HAIC-HIWC flight campaign (hereafter Darwin-2014) in Darwin, Australia using the SAFIRE Falcon 20 aircraft. The flight program was successfully conducted between 16 January and 18 February 2014, but fell short of its data collection goal due to an engine failure unrelated to engine icing. A total of 23 flights were conducted, mostly in large tropical mesoscale convective systems (MCSs). In addition to a new IKP2 TWC measurement device (described in the next section), the Falcon 20 cloud measurement instrument suite included a Droplet Measurement Technologies (DMT) Cloud Droplet Probe (CDP-2; 2$49 \mu \mathrm{m})$, a Stratton Park Engineering Co. 2D-S imaging probe (10-1280 $\mu \mathrm{m})$, and a DMT Precipitation Imaging Probe (PIP; $100-6400 \mu \mathrm{m})$. A Science Engineering Associates Robust hot-wire probe (Strapp et al., 2008; Grandin et al., 2014) provided backup TWC measurements. The RASTA (RAdar Sys-
Tem Airborne) research W-band radar (Protat et al., 2004) provided Doppler and reflectivity radar measurements from six antennae.

The second HAIC-HIWC flight campaign (hereafter Cayenne-2015) was conducted from 5-29 May 2015 out of Cayenne, French Guiana. Two aircraft collected cloud in situ data from this campaign: the Falcon 20 with approximately the same instrument suite as described above, and the National Research Council of Canada Convair-580 aircraft, also equipped for cloud in situ and remote sensing. The details of the many Convair instruments will not be provided here, but it carried a second copy of the IKP2 probe for primary TWC measurements, and the CDP-2, 2D-S, and PIP for particle size distribution measurements. A total of 17 Falcon 20 and 10 Convair-580 flights provided data from oceanic MCS and continental storms that were suitable for the HIWC cloud analysis.

The NASA HIWC-RADAR flight campaign (hereafter Florida-2015) was conducted from 12 to 28 August 2015, with a base of operations in Fort Lauderdale, Florida. The NASA DC-8 aircraft was equipped with the IKP2 TWC probe, CDP-2, 2D-S, and PIP as primary cloud in situ instrumentation. A total of 10 flights were conducted off the southeast coast of the USA, the Gulf of Mexico, and over the Caribbean. Although the primary objective of this campaign was to test pilot radar technologies, the project adopted the same cloud measurement strategies, focusing on oceanic MCS. The measurements included four flights in tropical storms Danny and Erika.

The overall objective of the three flight campaigns was to collect data to support the aviation industry objectives, and thus the flights were designed and funded with the first priority to collect cloud characterization data in the types of clouds that cause engine events, and in regions of those clouds that would be similar to what a commercial aircraft pilot might traverse. These objectives were not necessarily compatible with collection of the best scientific data. The flight plans, described in the HIWC Science and Technical Plan (Strapp et al., 2016a), were adopted for all three campaigns. The plans call for quasi straight-and-level runs across convectively active regions of tropical oceanic MCS clouds, similar to those described by Grzych and Mason (2010). These runs were to be aligned with regions of expected heavy rain below the aircraft, but through at most low reflectivity "green" echoes on the pilot's radar. The pilot was given the discretion to optimize the run using his radar, and set up a pattern of reciprocal runs to survey this suspected area of HIWC. If regions of high radar reflectivity were observed at flight altitude, the pilot was instructed to traverse the system at a conventional safe proximity from the reflectivity core. Regions of lightning were to be avoided. The objective was to collect at least one hundred $32.2 \mathrm{~km}$ data segments (a regulatory reference distance) at each of the four primary temperature layers $-50,-40,-30$, and $-10^{\circ} \mathrm{C}$, $\pm 5^{\circ} \mathrm{C}$ (in order of priority). The combination of the three 
projects achieved the data collection objectives, with a total of more than $54800 \mathrm{~km}$ of in-cloud data in mostly tropical oceanic MCS.

\subsection{In situ total water content measurements}

The measurements of these flight campaigns were expected to be dominated by ice particles in concentrations that could, at least in theory, reach $8-9 \mathrm{~g} \mathrm{~m}^{-3}$ in the unlikely event that deep adiabatic cores were encountered. Although various methods have been used to make airborne TWC estimates, including evaporators, these measurements have been especially problematic in a high-altitude, high-speed, HIWC environment, and lack substantive information on absolute accuracy. The aviation group tasked to develop the technology plan that recommended the flight measurement campaigns examined reliability and accuracy information for existing airborne TWC instruments and concluded that a new instrument was required to reduce risk and provide more defensible accuracy. It was therefore decided to develop a new TWC instrument specially designed for this environment.

The new prototype isokinetic TWC evaporator (IKP1) was designed specifically for the high-altitude, high-speed, HIWC environment, with a design goal of $20 \%$ accuracy at $10 \mathrm{~g} \mathrm{~m}^{-3}, 20 \mathrm{KPa}$, and $200 \mathrm{~m} \mathrm{~s}^{-1}$ true airspeed (Davison et al., 2008, 2010). The probe was downsized to a second version (IKP2) for use on the Falcon 20 aircraft, and then successfully tested in a series of wind tunnel experiments, exposing it to IWCs as high as $15 \mathrm{~g} \mathrm{~m}^{-3}$ under highaltitude flight conditions (Strapp et al., 2016b). Accuracy estimates to date have been provided by Davison et al. (2016) and Strapp et al. (2016b). System accuracy estimates predict no more than $10 \%$ error at all TWC values larger than about $0.1 \mathrm{~g} \mathrm{~m}^{-3}$ for temperatures colder than $-30^{\circ} \mathrm{C}$. At warmer temperatures, uncertainty rises due to the increasing magnitude of the background humidity, which must be subtracted from the IKP2 humidity signal. This produces a baseline uncertainty, limiting the practical use of the probe to about $0{ }^{\circ} \mathrm{C}$ and colder, with the greatest effect on low TWC measurements. For the flight programs described herein, the IKP2 was the primary instrument for the TWC measurements (Strapp, 2016a, b, 2017); it has so far been concluded that it provided high TWC measurements at the desired accuracy within the target $\left(-10\right.$ to $\left.-50^{\circ} \mathrm{C}\right)$ temperature intervals.

The measurements of the three campaigns have revealed that ice particles dominated the TWC in the large deep convective clouds sampled. Mixed phase regions were narrow and infrequent, and contained only low liquid water contents. In this regard, the terms HIWC and high TWC are synonymous for the purposes of this paper. HIWC will be used as a generic term to denote the condition, and high TWC will be used when referring to the measurement.

TWC values measured during the flight program reached a maximum of about $4.1 \mathrm{~g} \mathrm{~m}^{-3}$ over a $0.93 \mathrm{~km}$ distance scale, the shortest scale length that is provided for this dataset.

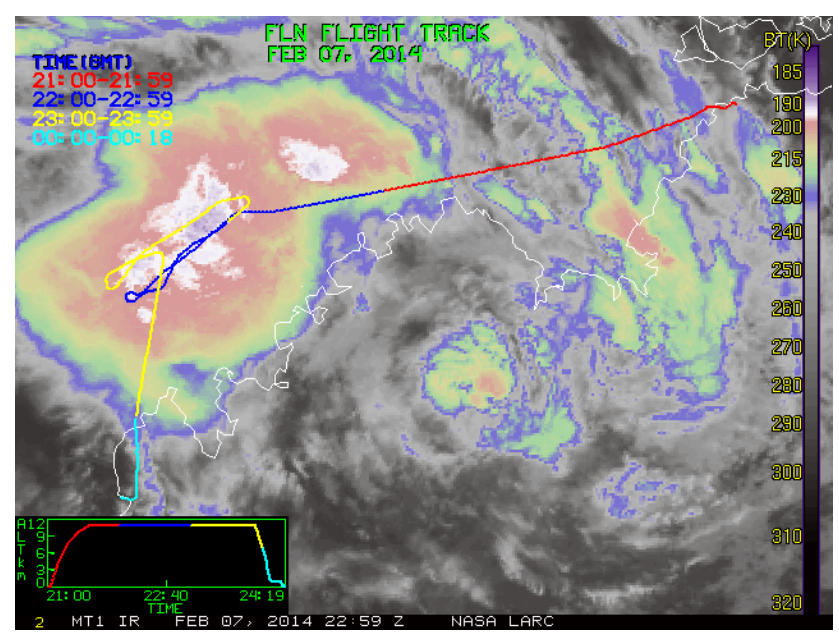

Figure 1. Flight track of the Falcon 20 on 7 February 2014, which departed from Darwin, Australia (red segment) and landed in Broome (cyan segment), overlaid upon a MTSAT-1R JAMI colorenhanced BTW image at 22:59 UTC. The track is color coded by the time of observation specified in the upper-left.

Extended periods of HIWC, defined as TWC $\geq 1.0 \mathrm{~g} \mathrm{~m}^{-3}$, were not uncommon, with $92.6 \mathrm{~km}$ averaged TWC values reaching as high as $2.3 \mathrm{~g} \mathrm{~m}^{-3}$. An example of a flight pattern conducted during Darwin-2014 Flight 16 is shown in Fig. 1. The IR image is color-enhanced such that the broad white area with embedded purple is at $-78^{\circ} \mathrm{C}$ or colder, this temperature threshold being an overall informal estimate of the convective equilibrium level used during the project, and about $7^{\circ} \mathrm{C}$ warmer than the value estimated for this day. The WMO-defined (World Meteorological Organization, 1957) and cold point tropopause values were about -76 and $-90^{\circ} \mathrm{C}$ respectively from the nearby Broome, Australia 8 February 2014 00:00 UTC radiosonde. In this case, the distance the aircraft traversed through clouds defined by the white area of the image are unusually long for this project at about $140 \mathrm{nmi}$. The peak TWC observed during this flight was approximately $2.5 \mathrm{~g} \mathrm{~m}^{-3}$, and there were particularly long periods of sustained TWC greater than $1.5 \mathrm{~g} \mathrm{~m}^{-3}$ (see Fig. 8c).

\subsection{Satellite observations and derived products}

During the field campaigns, satellite data were ingested and analyzed in near-real time to provide mission planning support and post-mission studies. The data were utilized on site and distributed to various science team groups via the internet, where they remain available in digital and image formats (http://satcorps.larc.nasa.gov).

\subsubsection{Satellite imager observations}

Multispectral GEO satellite observations from the MTSAT1R JAMI, and GOES-13 and GOES-14 Imagers are used 
Table 1. The spectral channels, temporal and spatial resolution, of the two satellite imagers used in this study and the geographic bounds of the study domains.

\begin{tabular}{|c|c|c|c|c|}
\hline $\begin{array}{l}\text { Satellite (and HAIC and/ } \\
\text { or HIWC campaign) }\end{array}$ & $\begin{array}{l}\text { Central wavelength of } \\
\text { spectral channels }\end{array}$ & Temporal resolution & $\begin{array}{l}\text { IR (and VIS) spatial } \\
\text { resolution at satellite nadir }\end{array}$ & $\begin{array}{l}\text { Domain covered } \\
\text { by flights }\end{array}$ \\
\hline $\begin{array}{l}\text { MTSAT-1R } \\
\text { (Darwin-2014) }\end{array}$ & $\begin{array}{l}0.72,3.8,6.8,10.8, \\
12.0 \mu \mathrm{m}\end{array}$ & $10 \mathrm{~min}$ & $4 \mathrm{~km}(1 \mathrm{~km})$ & $\begin{array}{l}20-10^{\circ} \mathrm{S} \\
120-145^{\circ} \mathrm{E}\end{array}$ \\
\hline $\begin{array}{l}\text { GOES-13 } \\
\text { (Cayenne-2015) }\end{array}$ & $\begin{array}{l}0.63,3.9,6.5,10.7, \\
13.3 \mu \mathrm{m}\end{array}$ & $30 \mathrm{~min}$ & $4 \mathrm{~km}(1 \mathrm{~km})$ & $\begin{array}{l}3^{\circ} \mathrm{S}-10^{\circ} \mathrm{N} \\
46-58^{\circ} \mathrm{W}\end{array}$ \\
\hline $\begin{array}{l}\text { GOES-13 and GOES-14 } \\
\text { (NASA HIWC-RADAR, Ft. } \\
\text { Lauderdale, Florida 2015) }\end{array}$ & $\begin{array}{l}0.63,3.9,6.5,10.7 \\
13.3 \mu \mathrm{m}\end{array}$ & $\begin{array}{l}1,7.5,15 \text {, } \\
\text { or } 30 \text { min (flight day } \\
\text { and satellite dependent) }\end{array}$ & $4 \mathrm{~km}(1 \mathrm{~km})$ & $\begin{array}{l}14-33^{\circ} \mathrm{N} \\
55-95^{\circ} \mathrm{W}\end{array}$ \\
\hline
\end{tabular}

to analyze convective cloud characteristics for a variety of observed IWC conditions and to produce the cloud property retrieval and overshooting convective cloud top (OT) detection products described below. Observations from the visible (VIS) and four infrared (IR) JAMI and GOES spectral channels are used to derive these products. These data were acquired from the University of Wisconsin Space Science and Engineering Center using the Man-computer Interactive Data Access System-X (McIDAS-X, Lazzarra et al., 1999). Table 1 summarizes the spectral channels, the spatial and temporal resolution of the observations, and the geographic boundaries of domains of interest for the HAICHIWC Darwin-2014, Cayenne-2015, and NASA HIWCRADAR Florida-2015 flight campaigns. The Meteosat Second Generation (MSG) SEVIRI also observed the Cayenne2015 campaign domain at 15 min intervals, but its data were not used in this study for the following reasons: (1) MSG observes this domain at a very oblique angle $\left(61^{\circ}\right)$ which can adversely impact cloud property retrieval accuracy and increase parallax errors, and (2) the MSG $1 \mathrm{~km}$ VIS data required for daytime OT detection is unavailable for most of the daylight hours over this region.

\subsubsection{Satellite-derived cloud property retrievals}

Cloud properties are retrieved from $4 \mathrm{~km}$ resolution GOES and MTSAT JAMI imager radiances for pixels classified as cloudy using the Satellite ClOud and Radiation Property retrieval System (SatCORPS) that identifies cloudy pixels (Minnis et al., 2008a, b), retrieves the cloud properties (Minnis et al., 2008b, 2011), and estimates radiative fluxes from multispectral satellite imagery. For daytime portions of the images, defined as solar zenith angle $(\mathrm{SZA}) \leq 82^{\circ}$, the Visible Infrared Shortwave-Infrared Split-Window Technique (VISST) is used to retrieve cloud properties such as thermodynamic phase, cloud optical depth (COD), ice particle or water droplet effective radius $\left(R_{\text {eff }}\right)$, cloud height, pressure, temperature, and geometric thickness. The Solar Infrared Split-Window Technique (SIST) is used to retrieve these parameters at night. It is important to note that the SIST IR-only COD is limited to values of approximately six and therefore is insensitive to optical depth variations within optically thick deep convective cloud tops, so only daytime VISST COD is employed in our study. The $1 \mathrm{~km}$ VIS data provided by GOES and MTSAT were subsetted to $4 \mathrm{~km}$ to match the resolution of the IR channels. The cloud phase algorithm classifies a cloudy pixel as either "liquid" or "ice" based on the cloud-top temperature and $R_{\text {eff }}$ information. Optically thick clouds containing both liquid and ice are generally classified as ice clouds since the current version of the retrieval algorithm is unable to separately classify mixedphase clouds. Ice water path (IWP) is not directly retrieved by VISST but is rather a parameter derived from COD and $R_{\text {eff }}$ that is intended to represent the total amount of water within the depth of vertically homogeneous clouds classified as having ice tops. Cloud phase is combined with aircraft air temperature observations to ensure that both satellite and aircraft were sampling glaciated clouds. Full descriptions of VISST and SIST are provided by Minnis et al. (2011). For ice clouds, the reflectance model based on severely roughened hexagonal ice columns (Yang et al., 2008) replaces the smooth crystal model used in Minnis et al. (2011).

The VISST COD retrieval is designed to translate the observed VIS reflectance into COD through the use of cloud microphysical models and knowledge of solar illumination and sensor viewing geometry. There can be significant spatial variability in VIS reflectance within deep convective cloud tops due to shadowing induced by vertical perturbations such as gravity wave and OT signatures. This is especially true at high SZA when the sun-facing sides of the vertical perturbation are illuminated, enhancing VIS reflectance, while the other side is shadowed. The dark shadowed regions will yield a lower COD even though they have very similar cloud microphysics at the $4 \mathrm{~km}$ pixel scale as the brighter regions. We show later in this paper that high TWC is more likely in high COD regions, so low COD induced by shadowing would adversely impact our daytime PHIWC diagnostic product. Therefore, we smooth the COD using a $5 \times 5$ pixel box, weighting the center of the box by nine, the inner three-pixel frame by three, and the outer five-pixel frame by one to preserve locally bright clouds but also to reduce shadowing artifacts. These weights were selected based upon empirical 
testing. Examples of the VIS reflectance, unsmoothed COD, and smoothed COD products are shown in Fig. 2. In the unsmoothed COD (Fig. 2e), OT regions and deep convection are identified by high COD but gravity waves and other textured/shadowed regions induce lower COD and what may be considered to be "noise". In the smoothed COD (Fig. 2f), the noise is greatly reduced but the high COD in deep convective anvils is preserved. The smoothing process does not remove the COD biases but it provides a more spatially coherent product which is our intent.

\subsubsection{Automated deep convection and overshooting cloud top detection methods}

Deep convective anvil clouds and embedded updraft (i.e., OT) regions are detected and analyzed within GEO imagery using several automated methods. A commonly used method for deep convective anvil detection is the brightness temperature difference (BTD) between the $\sim 6.5 \mu \mathrm{m}$ water vapor (WV) and $\sim 10.7 \mu \mathrm{m}$ window (BTW) channels (Schmetz et al., 1997; Martin et al., 2008). Comparisons of the BTD product with CloudSat Cloud Profiling Radar observations indicate that positive BTD values are effective for detection of deep convection, often with a cloud vertical thickness exceeding $12 \mathrm{~km}$ (Young et al., 2012). This method has not proven to be effective for differentiating overshooting cloud tops (OT) from deep convective anvils (Bedka et al., 2010; Setvak et al., 2013), but increasingly positive BTD values have been correlated with intense storms and a higher likelihood of lightning (Machado et al., 2009).

An automated satellite-based OT detection method has been used to identify the locations of anvil clouds and deep convective updrafts within these clouds (Bedka and Khlopenkov, 2016). OTs often appear in satellite imagery as small clusters of pixels having cold BTW and enhanced texture in the VIS channel relative to the surrounding anvil, which has much more uniform BTW and smoother texture. A set of statistical, spatial, frequency analyses were developed to identify clouds that could be within convection and to detect embedded BTW minima and textured regions. A set of OT candidate regions corresponding to local BTW minima are initially defined. The region around OT candidates is then analyzed to define the spatial extent of the anvil cloud. The anvil cloud boundary is identified by a rapid BTW increase indicative of anvil edge or sharp BTW fluctuations indicative of breaks in the anvil between neighboring storms. OT candidate regions that pass an extensive set of tests that quantify how closely a candidate resembles a typical OT are assigned a final "OT Probability" based on three parameters: the temperature differences between the OT candidate minimum BTW and (1) the surrounding anvil mean BTW, (2) the tropopause temperature derived from the WMO lapse-rate definition, and (3) the most unstable equilibrium level temperature. Parameters 2 and 3 are derived from the ModernEra Retrospective Analysis for Research and Applications
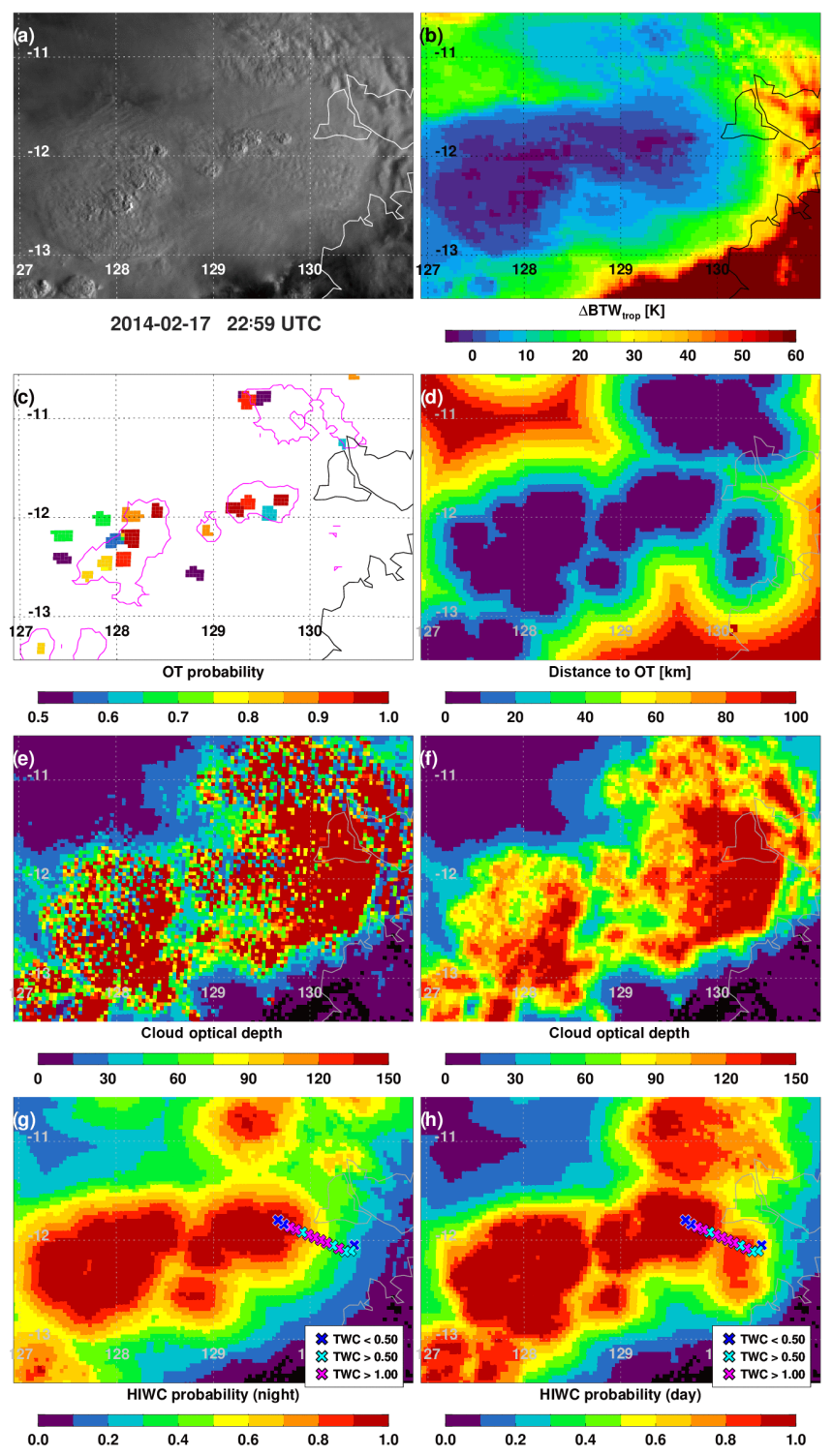

Figure 2. A series of MTSAT-1R JAMI observations and derived products for an image during Falcon 20 Flight 22 of Darwin-2014, timestamped at 22:59 UTC but valid over Australia at 23:02 UTC on 17 February 2014. (a) $0.73 \mu \mathrm{m}$ VIS reflectance, (b) the difference between the $10.8 \mu \mathrm{m}$ IR BT and MERRA tropopause temperature ( $\triangle \mathrm{BTW}$ ), (c) OT Probability $\geq 0.5$ (colored shading) and VIS Rating $\geq 5$ (magenta contours), (d) dOT, (e) original unsmoothed COD, (f) smoothed COD, (g) PHIWC Pight $_{\text {, and (h) PHIWC }}$.ay. Panels (g) and (h) are overlaid with $45 \mathrm{~s}$ mean TWC observations from 22:57 to 23:07 UTC.

data (MERRA, Rienecker et al., 2011), but these parameters could also be derived from any analysis or forecast for realtime applications. The OT Probability product was trained on a large sample of OT signatures and non-OT anvil cloud, with the intent to assign high probability to prominent OT signatures and low probability to subtle within-anvil BTW minima that are less likely to be an OT. Of the three parameters listed 
above, the OT-anvil BTW difference has the greatest impact on OT Probability.

The texture in VIS imagery is quantified via a unitless "VIS Rating". The VIS Rating product is based on pattern recognition within Fourier transform analyses of small windows $(32 \times 32 \sim 1 \mathrm{~km}$ VIS pixels) of pixels with VIS reflectance consistent with optically thick anvils observed at a particular location and time of day/year. OTs and gravity waves produce a unique signature within the Fourier spectrum, and the prominence of this signature is quantified to derive the VIS Rating. Although VIS Rating values can exceed 50 for the most prominent OTs that penetrate the tropopause by $2+\mathrm{km}$ (Sandmael et al., 2017), values greater than seven were found within a majority of human-identified OTs (Bedka and Khlopenkov, 2016). Values as low as five identify enhanced cloud-top texture indicative of vertical motions within the cloud or gravity waves and possible generation of HIWC, but these low VIS Rating regions often do not correspond with the classic "cauliflower-like" signature that a human would consider to be an OT. The VIS imagery is processed at its original $1 \mathrm{~km}$ resolution within the OT texture detection algorithm, but the maximum VIS Rating for each $4 \mathrm{~km}$ IR pixel region is recorded in the final VIS Rating product.

The OT detection algorithm offered a $69 \%$ POD and $18 \%$ FAR when high probability $(\geq 0.7)$ BTW-based OT detections were compared against a large sample of human OT identifications within $0.25 \mathrm{~km}$ MODIS VIS imagery in Bedka and Khlopenkov (2016). These accuracy statistics are based on automated detections using MODIS imagery sampled to a $4 \mathrm{~km}$ resolution, representative of MTSAT JAMI and GOES imager data analyzed in this paper. The POD and FAR changed to 51 and $2 \%$, respectively, when high OT Probability detections were collocated with VIS Rating, illustrating that VIS texture detection can be used during daytime to confine the BTW-based product almost exclusively to OT regions. Areas with a non-zero VIS Rating outside of human-identified OT regions in GOES-14 imagery often coincided with regions of $>30 \mathrm{dBZ}$ radar echoes at a $10 \mathrm{~km}$ altitude for a case over the US, indicating the presence of strong updrafts (Bedka and Khlopenkov, 2016). In this paper, we will consider an "OT or texture detection" to be an OT Probability $\geq 0.5$ or VIS Rating $\geq 5$ to attempt to capture all regions within or near strong vertical motions that generate detectable perturbations within the satellite-observed cloud top. Bedka and Khlopenkov (2016) provide a more comprehensive OT detection algorithm description and additional product examples.

Within an anvil cirrus cloud, BTW is well correlated with the level of neutral buoyancy temperature, which can vary regionally and seasonally (Takahashi and Luo, 2012; Bedka and Khlopenkov, 2016). Therefore, use of a fixed BTW threshold to discriminate HIWC conditions will not work across the globe so the BTW must be normalized. The computation of the level of neutral buoyancy is very sensitive to
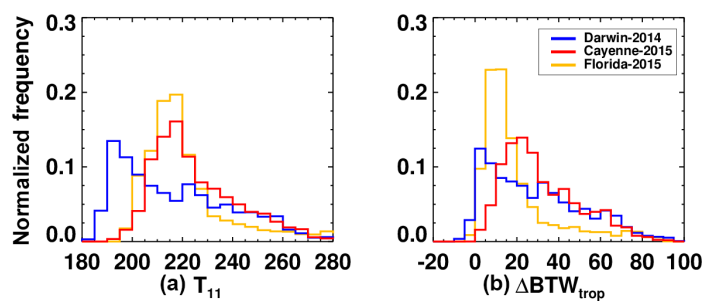

Figure 3. Distributions of BTW (a) and $\triangle \mathrm{BTW}$ (b) differentiated by HIWC and HAIC flight campaign using the colors shown in the legend.

the boundary layer temperature and moisture profile, and reanalyses such as MERRA may not capture the actual boundary layer structure present at the place and time of a satelliteobserved storm. These inaccuracies can bias the derived level of neutral buoyancy and adversely impact BTW normalization. A more temporally and spatially stable reference for BTW is the tropopause temperature. The difference between BTW and the MERRA tropopause temperature (denoted as $\triangle \mathrm{BTW}$ hereafter) provides a globally consistent metric of storm intensity. Distributions of BTW and $\triangle \mathrm{BTW}$ along aircraft tracks during the three flight campaigns are shown in Fig. 3. We have defined $\triangle \mathrm{BTW}$ as BTW minus the MERRA tropopause temperature, so negative $\triangle \mathrm{BTW}$ corresponds to cloud tops colder than the tropopause temperature. Clouds most frequently sampled in Darwin-2014 had cloud tops approximately $25 \mathrm{~K}$ colder than those from Cayenne- 2015 or Florida-2015 due to a higher mean level of neutral buoyancy and tropopause in the Darwin region. Normalizing BTW by the tropopause temperature shows that Darwin cloud tops were only about $5-10 \mathrm{~K}$ colder than Florida, but still much colder $(\sim 20 \mathrm{~K})$ than Cayenne.

Examples of MTSAT JAMI OT detection products for a specific time during a Darwin-2014 campaign flight are shown in Fig. 2c. The corresponding VIS reflectance and $\triangle \mathrm{BTW}$ images (Fig. 2a-b) show numerous OT signatures present within $\triangle \mathrm{BTW} \leq 5 \mathrm{~K}$ in the center and lower left. Highly textured cloud without evidence of a classic "cauliflower-like" OT signature is present in the upper right. Gravity waves are evident throughout the anvil cloud via ripples in VIS texture emanating away from OT regions. Areas within and near OTs and other textured regions are detected by the VIS Rating product (magenta contour, Fig. 2c). Especially cold and distinct BTW regions collocated with VIS Rating detections are assigned high OT probability $(>0.7)$. Several other localized cold spots outside of textured regions in cold cirrus outflow and gravity waves are assigned lower OT Probability. Bravin et al. (2015) concluded that HIWC must often be present in outflow near to OT regions that are considered safe to traverse by pilots due to the presence of weak or non-existent echoes from onboard pilot-radar systems. We developed a distance-from-the-nearest OT (dOT) product (Fig. 2d) to quantify dOT-HIWC relationships and 
verify the findings of Bravin et al. (2015) using a much larger sample size. The dOT product will be discussed extensively in Sect. 3.

\subsection{Satellite and aircraft collocations}

Satellite observations, cloud property retrievals, and OT detections were collocated with the aircraft TWC observations to characterize satellite-derived cloud conditions for a range of TWC and to develop the PHIWC product. The $4 \mathrm{~km}$ nominal resolution of the satellite observations is far too coarse to resolve details at the $0.93 \mathrm{~km}$ scale of aircraft TWC observations. The $5 \mathrm{~s}$ TWC observations were averaged to $45 \mathrm{~s}$ intervals, an approximately $8 \mathrm{~km}$ distance based on a nominal aircraft cruising speed, in order to reduce subpixel scale variability and derive values more representative of the area within a GEO imager pixel. The maximum allowed time difference between the aircraft measurements and matching satellite observations is equal to the temporal resolution of the imagery, listed in Table 1, with Cayenne-2015 sampled at the lowest frequency on average. The four nearest satellite pixels (i.e., a $2 \times 2$-pixel box) were matched to the mid-point of each of the $45 \mathrm{~s}$ segments and the mean cloud properties were computed within this box to account for uncertainty in cloud position within the time window. Parallax corrections were based on the retrieved cloud top height and pixel location relative to GEO satellite nadir.

It is important to consider only the matches where the aircraft was physically located within cloud, and not above cloud top or below cloud base. We consider a data point to be in-cloud when TWC $\geq 0.1 \mathrm{~g} \mathrm{~m}^{-3}$. In total, 5371 satelliteaircraft matched $45 \mathrm{~s}$ data points within cloud were derived from the 50 flights during the three flight campaigns. 4598 of the matches occurred during daytime, defined by $\mathrm{SZA} \leq 82^{\circ} .67 \%$ of the matches were used for PHIWC product training and the remaining $33 \%$ were used for validation, described in Sect. 3.5. We cluster our satellite datasets into three TWC categories with low, moderate, and high TWC defined as $0.1 \leq \mathrm{TWC}<0.5,0.5 \leq \mathrm{TWC}<1.0$, and TWC $\geq 1.0 \mathrm{~g} \mathrm{~m}^{-3}$, respectively, for discussion purposes. TWCs of $0.5,1.0$, and $2.0 \mathrm{~g} \mathrm{~m}^{-3}$ correspond to the 50th, 75th, and 95th percentiles, respectively, for this specific satelliteaircraft matched dataset. Note that the matched aircraftsatellite dataset discussed in this article is different from the dataset used for the HAIC-HIWC and NASA HIWCRADAR regulatory analysis. The latter will supersede the dataset of this article for any regulatory purposes.

\section{Results}

We begin our presentation of the results by showing comparisons of satellite observations, GEO satellite-derived products, and in situ aircraft observations for a flight during the Darwin-2014 campaign to demonstrate the set of satellite products most relevant for incorporation into the PHIWC diagnostic product. We then show how select satellite products relate to aircraft TWC using the 5371 matched data pairs. We follow with a description of the PHIWC diagnostic and conclude this section with PHIWC examples and validation.

\subsection{GEO satellite products and in situ TWC comparisons}

Flight 22 of the Darwin-2014 campaign, the Falcon 20 took off from Darwin around 21:45 UTC on 17 February 2014, sampled convective cells to the west over the Timor Sea, and returned to Darwin around 01:00 UTC on 18 February. A time series of observations and derived products using the satellite-aircraft matched dataset for Flight 22 is shown in Fig. 4. Cloud top heights were $\sim 16 \mathrm{~km}$ for the duration of the flight corresponding to BTW around $-80^{\circ} \mathrm{C}$ (Fig. $4 \mathrm{a}-$ b). TWC measurements were collected at two distinct flight levels, the first at $-30^{\circ} \mathrm{C}$ from 22:10 to $23: 45$ UTC and the second at $-40^{\circ} \mathrm{C}$ from 23:50 to 00:35 UTC (Fig. 4b), which were approximately $5-6 \mathrm{~km}$ below our cloud top estimate. There were eight periods when TWC exceeded $1 \mathrm{~g} \mathrm{~m}^{-3}$ and two periods, 22:30-22:45 and 23:15-23:50 UTC, when TWC was relatively low $\left(<0.25 \mathrm{~g} \mathrm{~m}^{-3}\right)$.

TWC is not well correlated with BTW, $\triangle \mathrm{BTW}$, or BTD during this flight, indicating that high TWC was present only in small regions within or beneath deep convective anvils (Fig. 4b-c, e-f). BTW was consistently less than $-80^{\circ} \mathrm{C}$ and $\triangle \mathrm{BTW}$ near $0 \mathrm{~K}$ but the TWC varied considerably with many periods of TWC near to or below $0.1 \mathrm{~g} \mathrm{~m}^{-3}$. From 23:15 to 00:00 UTC, BTD was greater than $+1 \mathrm{~K}$ but varied by $<1 \mathrm{~K}$ as TWC increased steadily from $\sim 0.01$ to $>1 \mathrm{~g} \mathrm{~m}^{-3}$. This $1 \mathrm{~K}$ BTD variability is extremely small and within the noise of the MTSAT-1R JAMI WV absorption channel (Ai et al., 2017), so the BTD is not useful for discriminating HIWC in this case.

High TWC was observed in many instances when the aircraft flew close to OT detections and in regions of high COD (Fig. 4g-h), showing that identification of small scale dynamical and microphysical variability in broad and very cold cloud tops is critical for discriminating HIWC conditions. The Falcon 20 was within $20 \mathrm{~km}$ of an OT detection from 22:20-22:30, 22:55-23:10, 23:50-00:05, and 00:3000:35 UTC and sampled high TWC in all four encounters. TWC $<0.2 \mathrm{~g} \mathrm{~m}^{-3}$ was observed during three other periods when the aircraft flew within $20 \mathrm{~km}$ of an OT (23:21, 23:42, and 23:47 UTC). The COD was generally above 100 for all eight HIWC periods, but there were short intervals when COD $>100$ and TWC $<0.25 \mathrm{~g} \mathrm{~m}^{-3}$, illustrating the challenge associated with using passive GEO imager observations for isolating HIWC conditions at a particular flight level. Sustained TWC minima around 22:35 and 23:15-23:40 UTC correspond to periods with the lowest COD (25-60) during the flight. For reference, COD $>37$ typically indicates deep convection (Hong et al., 2007) and values exceeding 100 in- 


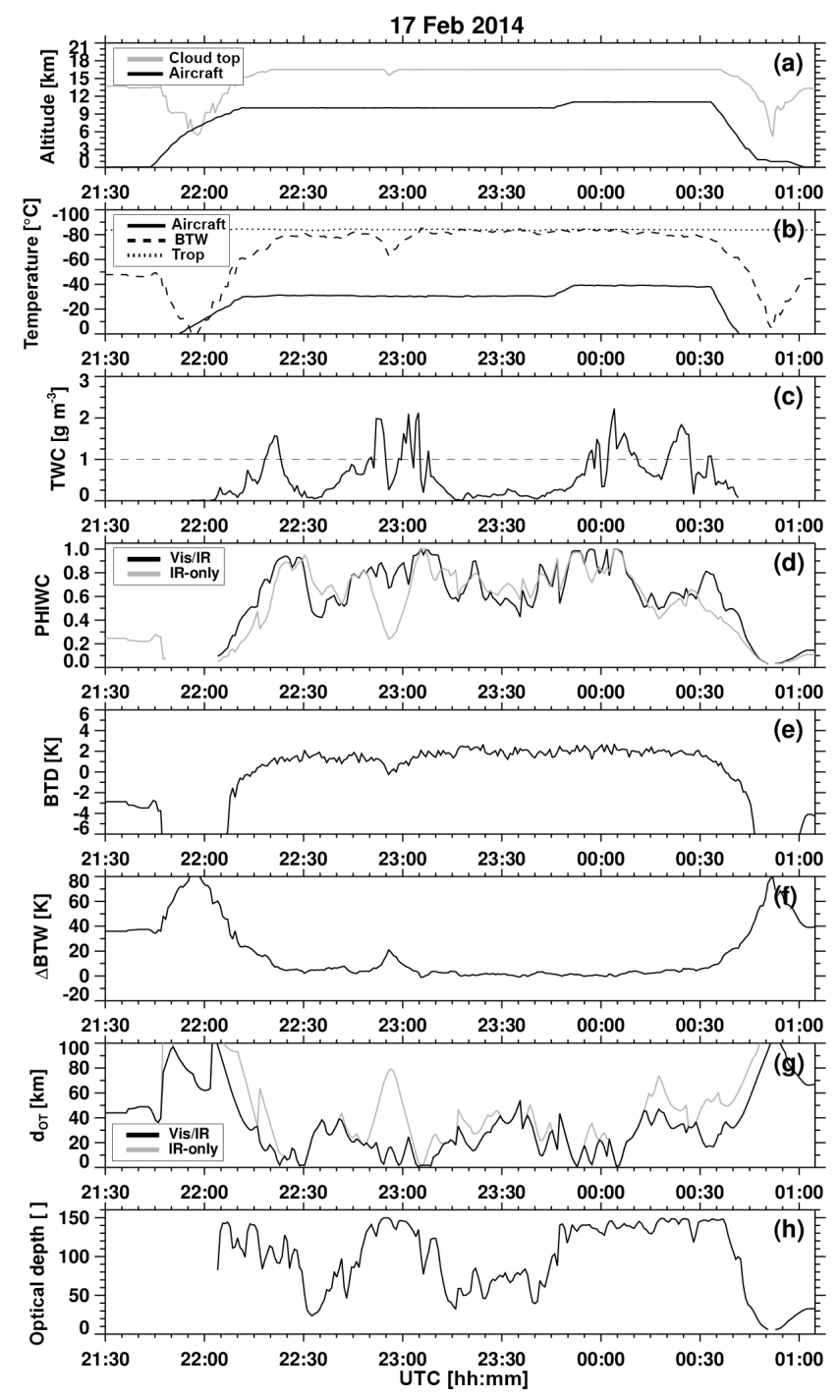

Figure 4. Time series of matched aircraft and satellite observations for Flight 22 of Darwin-2014 on 17-18 February 2014. (a) Satellite retrieval of cloud top height (grey) and the altitude of the Falcon 20 (black). (b) Satellite BTW observations (dashed), MERRA tropopause temperature analysis (dotted), and aircraft static air temperature observations (solid). (c) In situ $45 \mathrm{~s}$ averages of IKP2 TWC measurements. The dashed line indicates $\mathrm{TWC}=1 \mathrm{~g} \mathrm{~m}^{-3}$. (d) PHIWC day $_{\text {(black) and PHIWC }}$ night (grey), (e) WV-IRW BTD, (f) $\triangle \mathrm{BTW}$ (g) dOT VIS+IR (black) and IR-only (grey) and (h) smoothed COD. Major and minor tick marks represent halfhourly and $5 \mathrm{~min}$ intervals, respectively.

dicate extremely optically thick cloud at or near deep convective cores.

\subsection{Analysis of cloud properties as a function of TWC}

The analyses from Flight 22 on 17-18 February 2014 show that the BTD and $\triangle \mathrm{BTW}$ products identify broad deep convective anvil cloud regions while dOT and COD resolve smaller-scale structures within the anvil that are better correlated with TWC variability. Nevertheless, these results only represent one flight and it is important to examine how these and other parameters relate to TWC observed throughout the three flight campaigns. Figure 5 shows CFDs of satellite-derived cloud properties for low, moderate, and high TWC conditions. To aid interpretation of the CFDs, we focus on Fig. 5c which features the clearest separation between the three TWC intervals as a function of distance to the nearest OT pixel. This panel shows that $34 / 56 / 75 \%$ of low/moderate/high TWC events occurred within $10 \mathrm{~km}$ of an OT detection and $81 / 92 / 98 \%$ occurred within $50 \mathrm{~km}$ of an OT.

There is a clear separation between the satellite-derived cloud properties for the low TWC and the two larger TWC intervals for all satellite parameters except $R_{\text {eff }}$ (Fig. 5e). Low TWC values occur in warmer, less optically thick clouds that are farther from the nearest OT region than clouds with moderate or high TWC (Fig. 5a, d). IWP (Fig. 5f) is a parameter based on $R_{\text {eff }}$ and COD, so given that $R_{\text {eff }}$ provides no ability to discriminate between the TWC intervals, any separation between curves in the IWP plot is entirely driven by COD. Thus, despite the fact that de Laat et al. (2017) used IWP in their HIWC mask, we feel that IWP (as currently defined for satellite remote sensing) appears to be a redundant covariant with COD for HIWC identification. Thus, IWP is excluded from further consideration in the algorithm formulation.

Differences between the moderate and high TWC categories are quite small for $\triangle \mathrm{BTW}$ and BTD (Fig. 5b) but much greater for COD and dOT. High TWC occurred in flight within or beneath anvils that were slightly $(3 \mathrm{~K})$ colder, a bit more characteristic of deep convection $(0.2 \mathrm{~K}$ BTD increase), more optically thick ( $\sim 15$ COD units), and $6 \%$ more likely to be within $50 \mathrm{~km}$ of an OT region than moderate TWC events. Thus, it is clear that either moderate or high TWC can be present within or beneath deep convective cloud tops but high TWC occurs predominantly near updraft cores, textured gravity wave regions, and optically thick and thus ice-laden cirrus outflow.

\subsection{Probability of high ice water content (PHIWC) diagnostic product description}

The fundamental goal of the PHIWC diagnostic product is to optimally combine a set of satellite-derived parameters to assign high PHIWC to high TWC environments and much lower PHIWC to low and moderate TWC environments. The results from Fig. 5 show that our primary challenge will be differentiating moderate from high TWC, caused by the fact that GEO satellite imagers are most sensitive to cloud top and vertical integral parameters, leaving us to infer processes occurring within the cloud at flight level from temperature, reflectance, and spatial patterns at the cloud top. The most promising parameters to include in the PHIWC model are 

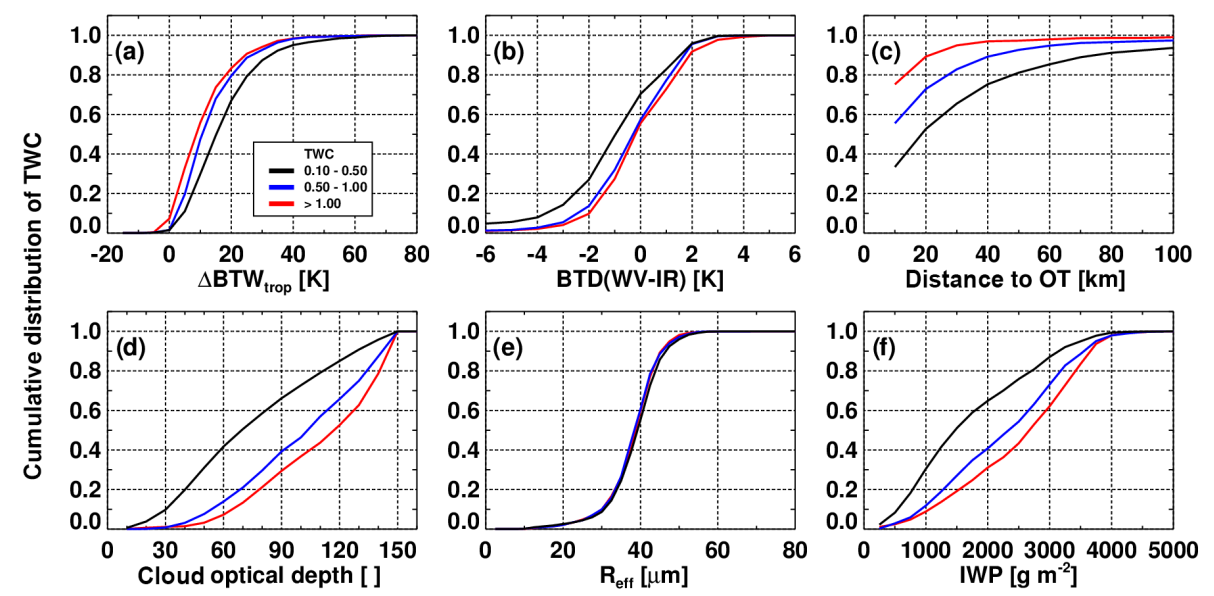

Figure 5. Cumulative frequency diagrams of satellite-derived (a) $\triangle$ BTW, (b) BTD, (c) dOT, (d) COD, (e) Reff, and (f) IWP for the three TWC intervals indicated in the legend in panel (a).

COD and dOT. We also include $\triangle \mathrm{BTW}$ to (1) address the fact that not every OT is accurately detected, so pixels with low $\triangle \mathrm{BTW}$ far from the nearest OT can still achieve a relatively high PHIWC; and (2) to provide additional information to the PHIWC model at night given that VIS-based predictors are unavailable. Previous studies (Bedka et al., 2010, 2012) and Fig. 5b show that BTD does not offer unique information beyond that provided by $\triangle \mathrm{BTW}$. In addition, the spectral coverage of WV channels across the global constellation of GEO imagers differs slightly which causes differences in the observed BTs, resulting in inter-satellite inconsistencies in PHIWC product output. For these reasons, BTD will not be considered further in the algorithm formulation.

Another way to view the relationships between COD, dOT, $\triangle \mathrm{BTW}$ and TWC is in the form of scatterplots, shown in the left panels of Fig. 6. TWC increases sharply as a cloud reaches a height within $15 \mathrm{~K}$ of the tropopause, but then only increases slightly as the cloud top reaches or exceeds the tropopause height. There were many observations of low TWC for $\triangle \mathrm{BTW}$ near $0 \mathrm{~K}$, so cold cloud temperatures alone are an insufficient discriminator of HIWC. TWC also generally increases with increasing COD, but significant scatter is evident. Scatter may be due to lingering "noise" within the COD field due to shadowing/texture that we were unable to smooth as described in Sect. 2.3.2. TWC $>0.5 \mathrm{~g} \mathrm{~m}^{-3}$ seldom occurs with COD $<37$, the Hong et al. (2007) deep convection criterion. The best HIWC discriminator appears to be the VIS +IR dOT, with a concentration of TWC $>0.5 \mathrm{~g} \mathrm{~m}^{-3}$ values at dOT $<10 \mathrm{~km}$. A VIS rating $\geq 5$ encompasses a much larger area than an IR OT detection which helps to explain the differences between the distributions for dOT with and without VIS information. Nevertheless it is extremely rare for more extreme TWC values $\left(\geq 2.0 \mathrm{~g} \mathrm{~m}^{-3}\right)$ to occur outside of a VIS+IR dOT of $20 \mathrm{~km}$, highlighting the importance of including detection of textured cloud tops in the PHIWC product.
For all parameters discussed here, a TWC threshold of $0.5 \mathrm{~g} \mathrm{~m}^{-3}$ (50th percentile of TWC, vertical dashed line in Fig. 6) appears to be a breakpoint in the distributions where the satellite-based parameters begin to lose sensitivity. A useful PHIWC product should be able to discriminate regions with TWC $\geq 0.5 \mathrm{~g} \mathrm{~m}^{-3}$. This TWC threshold is used to define a correct vs. false detection for the receiver operating characteristic (ROC) curve discussed in Sect. 3.5.

The right panels of Fig. 6 show boxplots of TWC as functions of $\triangle \mathrm{BTW}, \mathrm{COD}$, and dOT. The boxes indicate the 25th, 50th and 75th percentiles (Q1, Q2, and Q3, respectively) of TWC. The interquartile range (IQR) is given by Q3-Q1, and the lower and upper whiskers represent the extent of TWC values up to $\mathrm{Q} 1-1.5 \times \mathrm{IQR}$ and $\mathrm{Q} 3+1.5 \times \mathrm{IQR}$. TWC values outside of this range are outliers and plotted as circles. Mean TWCs are indicated as solid black dots. Using fits to the mean TWCs (magenta curves), we derived the mean TWC across a set of $\triangle \mathrm{BTW}, \mathrm{COD}$, and dOT intervals by inverting the axes on the scatterplots described above to derive a TWC "prediction" for a given parameter value (magenta curves, Fig. 6, right panels). These predictions are then combined to derive a final PHIWC for each satellite pixel using a fuzzy logic approach. Fuzzy logic has been used in another HIWC nowcast product (Algorithm for Prediction of HIWC Areas; ALPHA) currently in development at the U.S. National Center For Atmospheric Research (Rugg et al., 2017). Though it may not be clear in the scatterplot, TWC on average increases sharply as cloud tops approach the tropopause. Despite the scatter in COD, a linear relationship between the mean TWC and COD is evident. The mean TWC increases sharply within $40 \mathrm{~km}$ of an OT detection regardless of whether IR-only or VIS+IR OT detection is considered. The TWC increase when VIS dOT is included, however, is much sharper at a $0-40 \mathrm{~km}$ radius than the IR-only dOT. The dOT results are consistent with Bravin et al. (2015), who found that in-service engine power loss events occurred, on aver- 

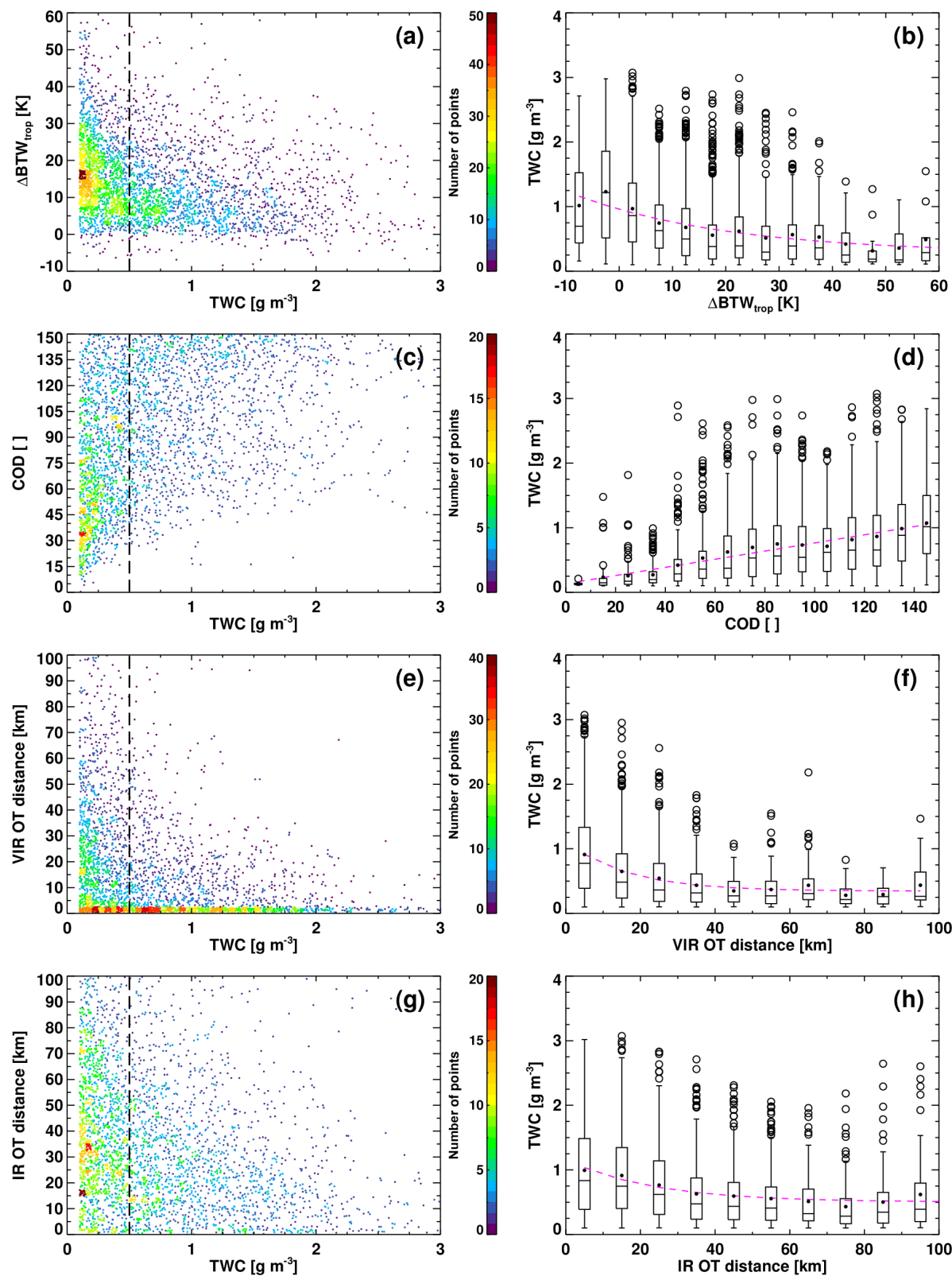

Figure 6. (a, c, e, g) The distribution satellite-derived parameter values as a function of $45 \mathrm{~s}$ mean TWC using the training dataset based on $67 \%$ of the satellite-aircraft match database (3580 samples). The color represents the density of points in a given region of the scatterplot. The vertical dashed line shows the $0.5 \mathrm{~g} \mathrm{~m}^{-3}$ threshold where satellite parameters start to lose sensitivity to TWC. (b, d, f, h) The distribution of TWC as a function of satellite-derived parameters. $\triangle \mathrm{BTW}, \mathrm{COD}$, dOT VIS+IR, and dOT IR are shown from top to bottom. The magenta lines provide a fit to the mean of the distributions and serve as PHIWC fuzzy logic membership functions.

age, $41 \mathrm{~km}$ from the center of locally colder and higher cloud regions embedded in the general cirrus canopy where OTs as described in this paper are often present.

We derive fuzzy logic membership functions for PHIWC based on the magenta curves in Fig. 6. The fits for $\triangle \mathrm{BTW}$ or dOT have the exponential form shown in Eq. (1) whereas the COD is linear as shown in Eq. (2), with $x$ corresponding to the $\triangle \mathrm{BTW}, \mathrm{dOT}$, or COD value, and coefficients $c_{1}-c_{3}$ listed in Table 2.

$\mathrm{TWC}=c_{1} \cdot c_{2}^{x}+c_{3}$

$\mathrm{TWC}=c_{1} \cdot x+c_{2}$

We then linearly rescale the TWC prediction values from Eq. (1) or (2) based on the TWC derived from the Table 2 maximum $\left(\mathrm{TWC}_{\max }\right)$ and minimum $\left(\mathrm{TWC}_{\min }\right)$ PHIWC thresholds. The net result is a PHIWC ranging from 0 to 1 for 
Table 2. Coefficients for deriving PHIWC values based on the fits shown by the magenta lines on Fig. 6 . $\triangle \mathrm{BTW}$, COD, and dOT values exceeding the max PHIWC threshold are assigned at PHIWC of 1.0. $\triangle \mathrm{BTW}$ and COD exceeding the min PHIWC Threshold are assigned a PHIWC of 0. Weights for Eq. (4) parameters are indicated in the last column. Weights for Eq. (5) parameters are indicated with an asterisk.

\begin{tabular}{lcccrrr}
\hline Parameter & $c_{1}$ & $c_{2}$ & $c_{3}$ & $\begin{array}{r}\text { max PHIWC } \\
\text { threshold }\end{array}$ & $\begin{array}{r}\text { min PHIWC } \\
\text { threshold }\end{array}$ & PHIWC weight \\
\hline$\Delta \mathrm{BTW}$ & 0.6953 & 0.9652 & 0.2789 & 0 & 90 & $0.375\left(0.700^{*}\right)$ \\
dOT $_{\text {VIS+IR }}$ & 0.7685 & 0.9411 & 0.3459 & 10 & 1000 & 0.300 \\
dOT $_{\text {IR-only }}$ & 0.6595 & 0.9582 & 0.5021 & 10 & 1000 & $0.300^{*}$ \\
COD $^{0.1332}$ & 0.0063 & & 100 & 0.25 & 0.325 \\
\hline
\end{tabular}

* Indicates weight for IR-only PHIWC.

each parameter using Eq. (3):

$$
\begin{aligned}
& \text { PHIWC }(\Delta \mathrm{BTW}, \mathrm{dOT}, \mathrm{COD})= \\
& \frac{\mathrm{TWC}^{-\mathrm{TWC}_{\min }}}{\mathrm{TWC}_{\max }-\mathrm{TWC}_{\min }}
\end{aligned}
$$

The PHIWC is set to 1.0 for parameter values at or above the maximum threshold. The PHIWC $(\triangle \mathrm{BTW}$ or COD) is set to zero for values at or below the minimum threshold because the matched TWC and satellite data show that it is extremely unlikely for HIWC to occur in such warm or optically thin clouds. The PHIWC(dOT) is set to 0.01 for values at or below the minimum threshold because the satellite imagery cannot resolve every OT nor can we detect them all with automated algorithms. A PHIWC(dOT) of zero would produce a final PHIWC of zero using Eqs. (4)-(5) below which would be undesirable.

The final PHIWC value is derived by multiplying the individual parameter PHIWC values together as shown in Eq. (4) for daytime imagery and Eq. (5) for nighttime imagery:

$$
\begin{aligned}
\mathrm{PHIWC}_{\mathrm{day}} & =\operatorname{PHIWC}(\Delta \mathrm{BTW})^{w_{1}} \cdot \mathrm{PHIWC}\left(\mathrm{dOT}_{\mathrm{VIS}+\mathrm{IR}}\right)^{w_{2}} \\
& \cdot \operatorname{PHIWC}(\mathrm{COD})^{w_{3}} \\
\mathrm{PHIWC}_{\text {night }} & =\operatorname{PHIWC}(\Delta \mathrm{BTW})^{w_{1}} \\
& \cdot \operatorname{PHIWC}\left(\mathrm{dOT}_{\mathrm{IR}-\text { only }}\right)^{w_{2}}
\end{aligned}
$$

The weights, $w_{1}, w_{2}$, and $w_{3}$ defined in Table 2 were derived using an iterative approach to maximize the area under the respective PHIWC $_{\text {day }}$ and PHIWC $_{\text {night }}$ ROC curves. $\triangle \mathrm{BTW}$ is the highest weighted parameter for $\mathrm{PHIWC}_{\text {day }}$ but adjusting the weights in favor of another parameter did not appreciably decrease the area under the ROC curve (AUC, discussed in Sect. 3.5). For PHIWC night $\triangle \mathrm{BTW}$ has more weight than dOT. Overall, the difference in AUC for all different weight combinations in the night and day products was less than 0.09 .

\subsection{PHIWC product examples}

Examples of the PHIWC $_{\text {night }}$ and PHIWC $_{\text {day }}$ products valid at 23:02 UTC (using the 22:59 UTC MTSAT JAMI scan) during Flight 22 of the Darwin campaign discussed in Sect. 3.1 are shown in Fig. 2g-h. The aircraft-measured TWC within \pm 5 min of the image time are overlaid on these graphs, showing seven high TWC (magenta X symbols) and other moderate TWC observations nearly coincident with this image. The Falcon 20 was flying northwestward toward an area of very cold cloud $(\triangle \mathrm{BTW}<5 \mathrm{~K})$. The highest $\mathrm{PHIWC}_{\text {night }}$ is concentrated near the coldest clouds and IR-only OT detections (Fig. 2c), as would be expected considering that dOT IR-only and $\triangle \mathrm{BTW}$ datasets are used to derive PHIWC night. Several high TWC observations were located in $\sim 20 \mathrm{~K} \triangle \mathrm{BTW}$ and relatively far $(\sim 80 \mathrm{~km})$ from an IR OT detection, combining to generate low $(\sim 0.3)$ PHIWC $_{\text {night }}$. The VIS image (Fig. 2a) shows prominent gravity waves emanating away from the OTs to the northwest. Very optically thick cloud (COD > 100) was coincident with all high TWC observations. Addition of these VIS-based products increased the $\mathrm{PHIWC}_{\text {day }}$ values to beyond 0.8 . There does not seem to be any obvious reason in the satellite-derived products to explain why some moderate TWC observations were embedded within a sequence of high TWC observations, again highlighting the challenges in differentiating moderate from high TWC conditions using VIS and IR observations of cloud tops.

The PHIWC time series (Fig. 4d) for Flight 22 of Darwin2014, described in Sect. 3.1, shows that both the PHIWC day and PHIWC $_{\text {night }}$ products featured local maxima $(>0.8)$ at or near all periods (45 s-8 min duration) when high TWC was observed. These maxima were driven by COD peaks and flight through or near OT and/or textured regions, given that $\triangle \mathrm{BTW}$ was fairly constant throughout the flight. There were many other situations when flights within optically thick clouds and low dOT measured low TWC. As seen in Fig. 2f, areas of high COD can be quite broad and do not always pinpoint the high TWC observed at the -30 to $-40^{\circ} \mathrm{C}$ flight levels. The dOT product is included in PHIWC to depict the proximity to active convective cells that are more likely to generate HIWC conditions. It is very possible that the OT detection products are correctly detecting OTs when low TWC is observed, but the aircraft is upwind of the convective core and thus is not observing the high TWC that may be present downwind. The PHIWC day $_{\text {and }}$ PHIWC $_{\text {night }}$ products were generally well correlated with each other ex- 


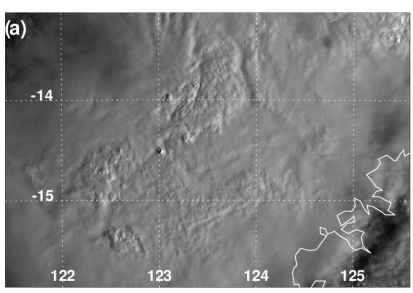

2014-02-07 23:09 UTC
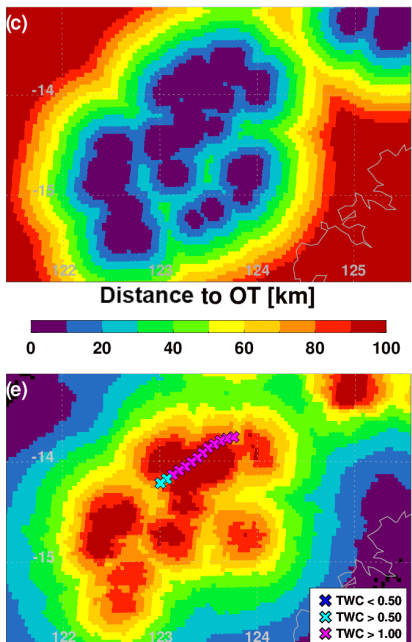

HIWC probability (night)
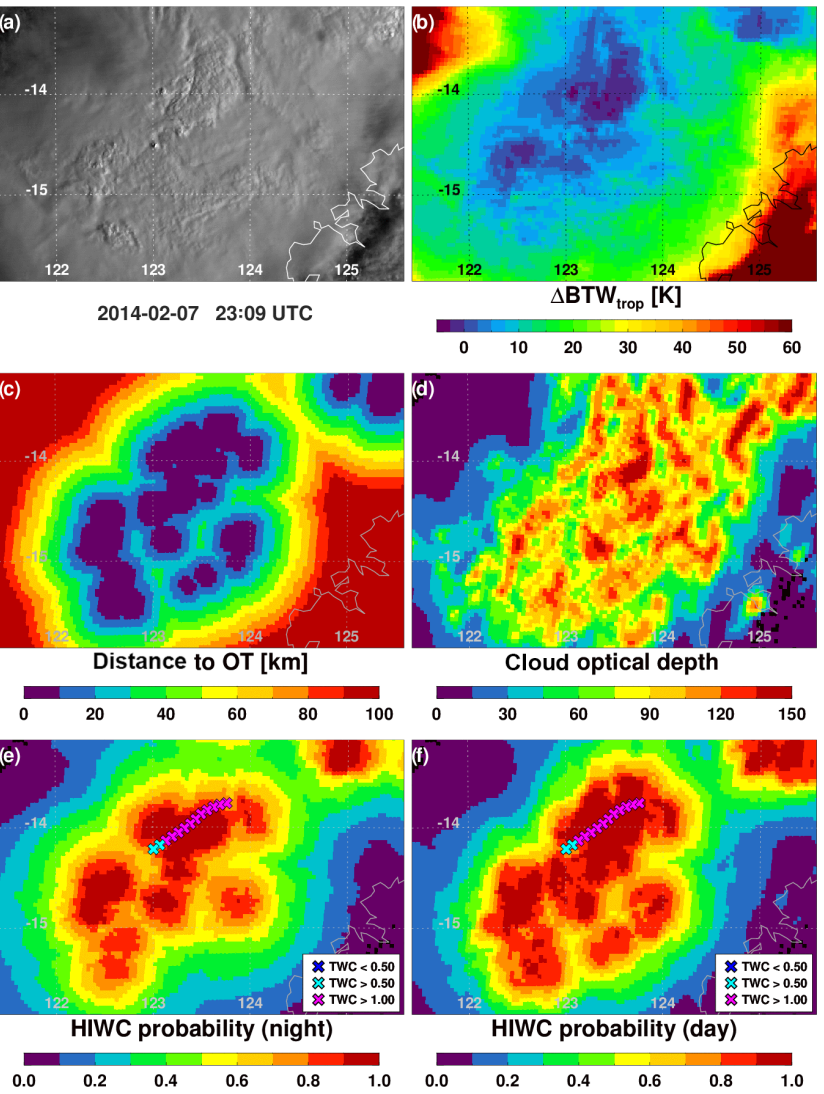

Figure 7. A series of MTSAT-1R JAMI observations and derived products for an image during Falcon 20 Flight 16, timestamped at 23:09 UTC but valid over Australia at 23:12 UTC on 7 February 2014. (a) $0.73 \mu \mathrm{m}$ VIS reflectance, (b) $\Delta \mathrm{BTW}$, (c) dOT,

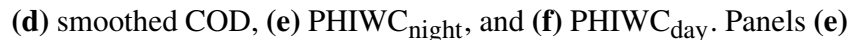
and (f) are overlaid with $45 \mathrm{~s}$ mean TWC observations from 23:07 to $23: 17$ UTC.

cept around 22:56 UTC, a time very near to that highlighted in Fig. 2. At 22:56 UTC, the nearest IR-only OT detection was $\sim 80 \mathrm{~km}$ away (Fig. $4 \mathrm{~g}$ ) with $\triangle \mathrm{BTW}$ near $20 \mathrm{~K}$ which combine to reduce $\mathrm{PHIWC}_{\text {night }}$.

An example of the PHIWC products and their inputs are shown in Fig. 7 for an image valid at 23:12 UTC on 7 February during Flight 16 of Darwin-2014, also featured in Fig. 1. The Falcon 20 flew very near to or within optically thick $(\mathrm{COD}>90)$ and textured clouds with $\triangle \mathrm{BTW}<5 \mathrm{~K} \Delta \mathrm{BTW}$. Texture and embedded BTW minima were detected well and the aircraft was frequently collocated with dOT $<20 \mathrm{~km}$. Unlike the scene shown in Fig. 2, high COD and texture, low $\mathrm{dOT}$, and extremely cold cloud were collocated, leading to a similar appearance between PHIWC $_{\text {day }}$ and PHIWC $_{\text {night }}$. High TWC was sustained for much of this flight segment and occurred within areas where PHIWC $>0.9$. PHIWC decreased slightly along the western edge of the segment in conjunction with a decrease to moderate TWC conditions.
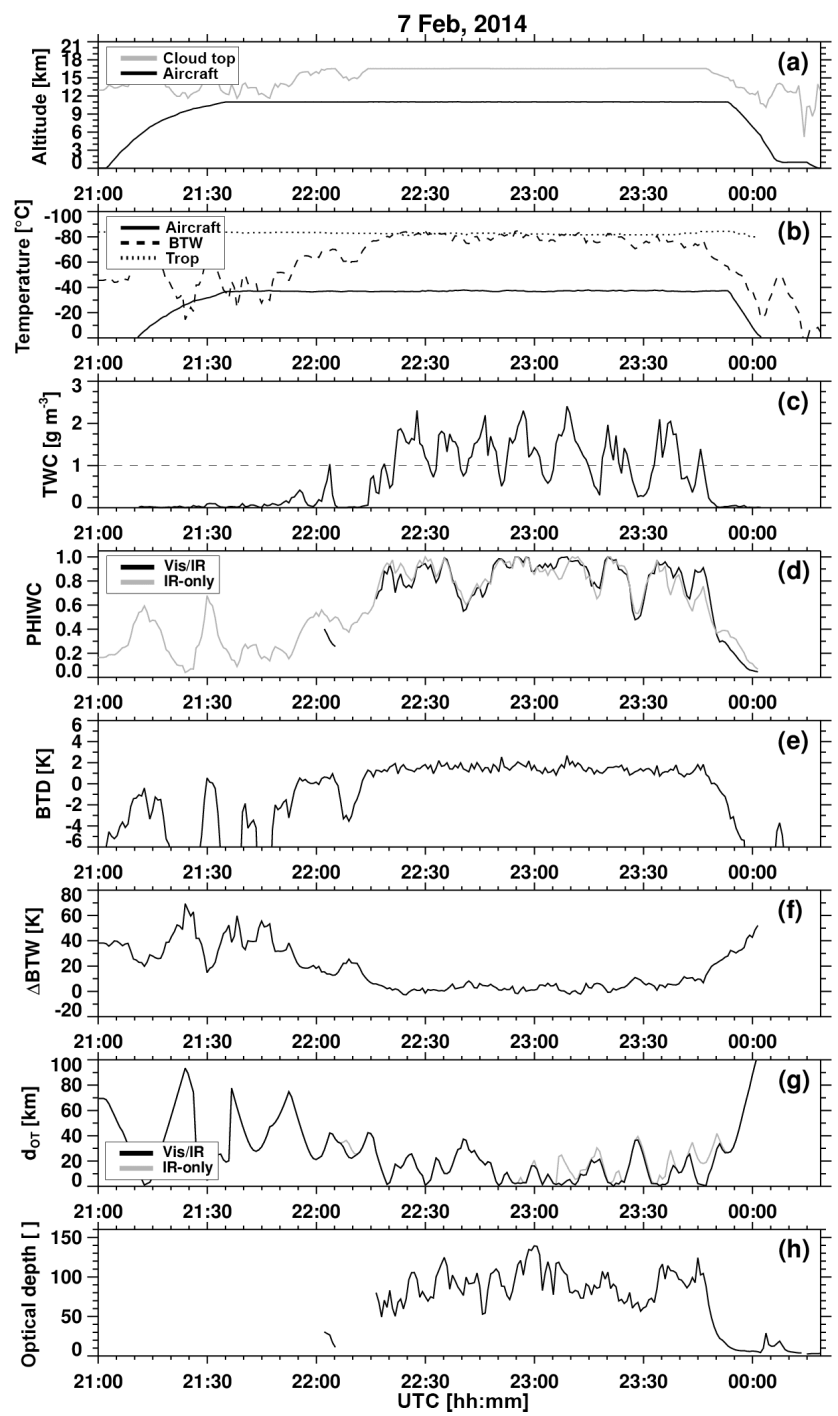

Figure 8. Time series of matched aircraft and satellite observations for Flight 16 of Darwin-2014 on 7-8 February 2014. The panels are the same as those described for Fig. 4.

A set of aircraft and satellite product time series for Flight 16 of Darwin-2014 are shown in Fig. 8. The aircraft sampled clouds at $-40{ }^{\circ} \mathrm{C}$ which was about $6 \mathrm{~km}$ below cloud top. There were ten individual high TWC encounters during this flight and HIWC conditions persisted for 7-10 min in many of the encounters. PHIWC $>0.8$ was present in nine of the ten encounters, with the exception being a twilight high TWC encounter at 22:04 UTC where $\triangle \mathrm{BTW}$ of $13 \mathrm{~K}$ and dOT IR-only of $40 \mathrm{~km}$ yielded a PHIWC of $\sim 0.4$. In general, the PHIWC time series was highly correlated with TWC except for a high TWC encounter near 22:45 UTC where lower COD $(\sim 50)$, slightly warmer than average $\triangle \mathrm{BTW}$, and $\mathrm{dOT}>20 \mathrm{~km}$ combined to produce $\sim 0.6$ PHIWC.

A segment from Falcon 20 Flight 19 of Cayenne-2015 shown in Fig. 9 illustrates an especially challenging case for 
satellite-based HIWC detection. The aircraft flew the long segment shown at approximately $-12{ }^{\circ} \mathrm{C}$ through an anvil cloud much warmer than those featured in Figs. 2 and 7. The anvil was textured with a few embedded OTs and exhibited high COD. High TWC was observed quite often during the 20 min segment. The PHIWC $C_{\text {night }}$ was extremely low $(\sim 0.3)$ in high TWC regions due to the relatively warm cloud and lack of distinct BTW minima and IR OT signatures. However, the high COD and texture increased PHIWC $_{\text {day }}$ to values over 0.75 throughout much of the region where high TWC was observed. This shows the value of VIS-based texture and COD products for capturing HIWC conditions in a cloud which forecasters would not consider to be especially active based on BTW data and spatial patterns alone.

A set of aircraft and satellite product time series for Flight 19 of Cayenne-2015 is shown in Fig. 10. The aircraft sampled clouds at $-12{ }^{\circ} \mathrm{C}(7.1 \mathrm{~km})$ during the first third of the flight and at $-44^{\circ} \mathrm{C}(11.7 \mathrm{~km})$ for much of the remainder. There were three (four) high TWC encounters at $-12{ }^{\circ} \mathrm{C}\left(-44^{\circ} \mathrm{C}\right)$. When the aircraft sampled at $-12^{\circ} \mathrm{C}$, TWC was much higher and sustained, on average, than during the rest of the flight. The corresponding values

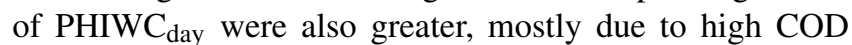
(>100). The PHIWC day during flight at $-44^{\circ} \mathrm{C}$ was correlated with TWC but the period of flight spanning 17:2017:40 UTC was conducted near the northwest region of the cloud where several new small quasi-isolated cells were observed, and consequently, strong gradients in TWC and coincident cloud properties are evident in the time series around 17:20, 17:27, and 17:35 UTC. Although the aircraft was very near OTs $(\mathrm{dOT}<20 \mathrm{~km})$ at these times, very low TWCs, $\triangle \mathrm{BTW}>30 \mathrm{~K}$, and cloud top heights sometimes below flight level (Fig. 10a) all indicate that the aircraft exited the cloud for brief periods in this region. PHIWC $_{\text {night was moder- }}$ ated by relatively high $\triangle \mathrm{BTW}>25 \mathrm{~K}$ even very near to OTs $(\mathrm{dOT}<20 \mathrm{~km})$ and did not exceed 0.70 throughout the entire flight. TWC of $1.4 \mathrm{~g} \mathrm{~m}^{-3}$ is an extreme value for $\triangle \mathrm{BTW}$ $>25 \mathrm{~K}$ and thus it is impossible to achieve a high PHIWC night in these conditions. High TWCs observed at around 18:30 were associated with a different cloud system near Cayenne.

Flight 5 on 19 August 2015 during the Florida-2015 campaign was observed by GOES-14 during an SRSOR period, which provided images at $1 \mathrm{~min}$ intervals for almost the entire flight. This high temporal resolution GOES-14 imagery enables precise matches between TWC and satellite products, virtually eliminating matching uncertainties, especially when compared to the $30 \mathrm{~min}$ match window used for the GOES-13 data from the Cayenne-2015 campaign. The NASA DC-8 sampled a long-lived but gradually decaying MCS over Louisiana and offshore regions over the Gulf of Mexico. Time series of the observations and derived products for this flight are shown in Fig. 11. The aircraft flew near the $-50^{\circ} \mathrm{C}$ level for the first third of the flight and then ranged from the -30 to $-50^{\circ} \mathrm{C}$ levels for the remainder. There were six high TWC periods observed dur-

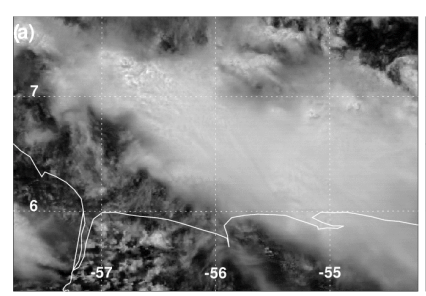

2015-05-23 16:15 UTC
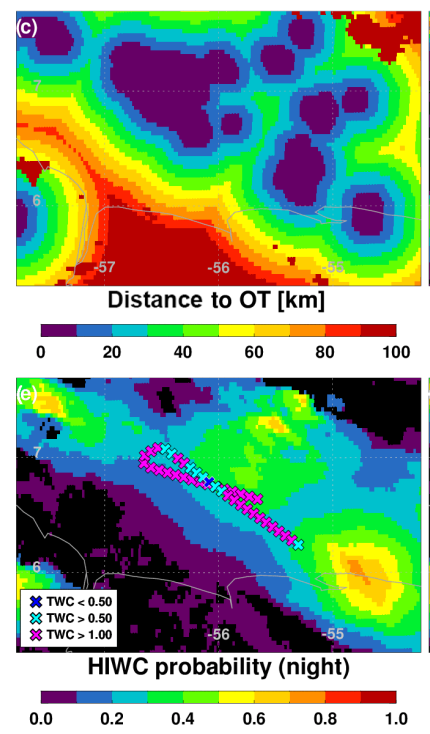

Figure 9. A series of GOES-13 observations and derived products for an image during Falcon 20 Flight 19 of Cayenne-2015, timestamped at 16:15 UTC but valid over French Guyana at 16:25 UTC on 23 May 2015. The panels are the same as those described for Fig. 7. The $45 \mathrm{~s}$ mean TWC observations are valid from 16:15 to 16:35 UTC.

ing the flight and all of these periods were collocated with PHIWC $_{\text {day }} \geq 0.8$ and PHIWC night $\geq 0.6$. Flight in dOT ranging from 0 to $20 \mathrm{~km}$ generally corresponded with periods of greater TWC. PHIWC day and PHIWC ${ }_{\text {night }}$ were often consistent in magnitude. The exception is the period from 15:10 to $15: 40$ UTC when the nearest IR-only OT was $30-60 \mathrm{~km}$ away but VIS texture was detected within $20 \mathrm{~km}$.

Animations of aircraft TWC observations, satellite observations and products, and the PHIWC products are available at these links (PHIWC $_{\text {day }}$ https://satcorps.larc.nasa.gov/ prod/website/yost/2015231/4-panel_VIS+IR/, PHIWC https://satcorps.larc.nasa.gov/prod/website/yost/2015231/

4-panel_IR/). These animations show that the PHIWC generally evolved quite smoothly due to a combination of the 1 min resolution of the imagery and the inclusion of $\triangle \mathrm{BTW}$ and COD; high values of COD were generally persistent in time. The dOT product induces periodic flickering of high PHIWC that might be considered noise, especially during night when optical depth is not available to constrain the PHIWC product. But it is important to acknowledge that OT 


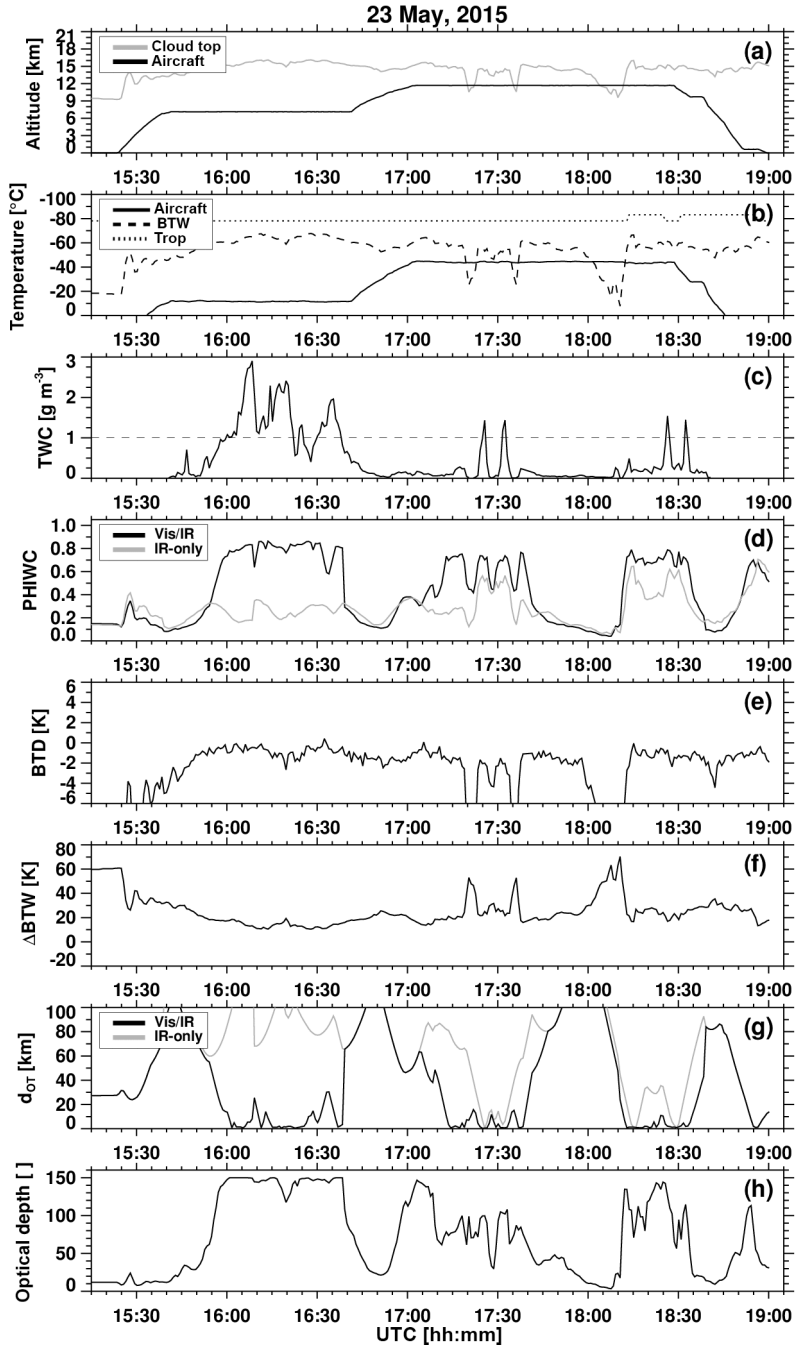

Figure 10. Time series of matched aircraft and satellite observations for Falcon 20 Flight 19 of Cayenne-2015. The panels are the same as those described for Fig. 4.

signatures can be quite short-lived so some PHIWC temporal variability should be expected especially in the vicinity of pulsating updraft regions far removed from other updrafts. Additional animations for Flight 4 on 16 August observed by GOES-14 are also provided at these links to further demonstrate product behavior with this extremely valuable and rare $1 \mathrm{~min}$ resolution data. (PHIWC $_{\text {day }}$ https://satcorps. larc.nasa.gov/prod/website/yost/2015228/4-panel_VIS+IR/, PHIWC $_{\text {night https://satcorps.larc.nasa.gov/prod/website/ }}$ yost/2015228/4-panel_IR/).

\subsection{PHIWC product validation}

The PHIWC products were validated using a simple comparison of the probability of detection (POD) and false alarm rate (FAR) for varying PHIWC thresholds. 17:71 nighttime and 15:71 daytime satellite-aircraft matches excluded from
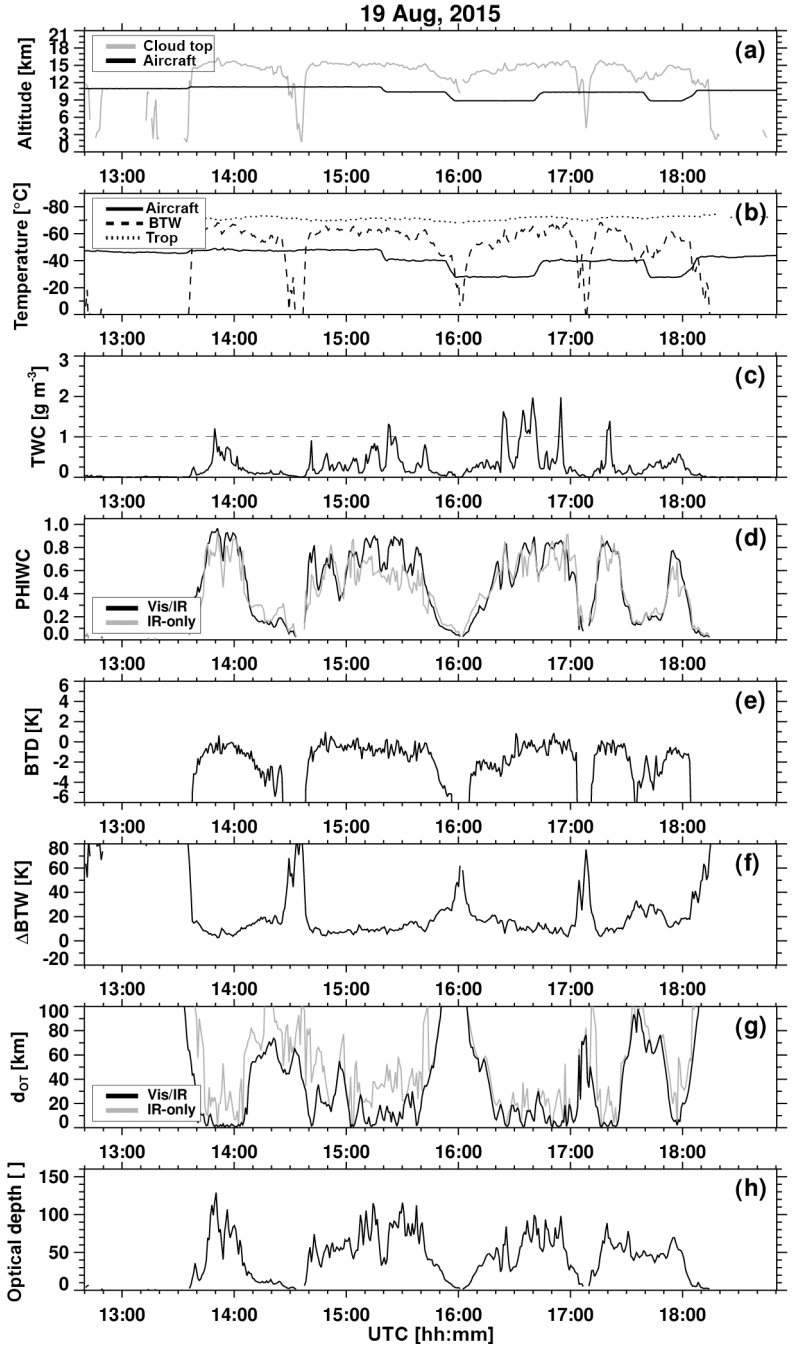

Figure 11. Time series of matched aircraft and satellite observations for Flight 5 of the Florida-2015 campaign on 19 August 2015. The panels are the same as those described for Fig. 4.

product training (see Sect. 2.4) were used for validation. As noted in Sect. 3.3, given that the satellite parameters show reduced sensitivity to TWC for moderate TWC values $\left(>0.5 \mathrm{~g} \mathrm{~m}^{-3}\right)$, we use $0.5 \mathrm{~g} \mathrm{~m}^{-3}$ to define a correct detection but we will also discuss results relative to the more realistic HIWC TWC threshold of $1.0 \mathrm{~g} \mathrm{~m}^{-3}$.

The ROC curves shown in Fig. 12 were constructed by plotting POD and FAR for thresholds chosen at intervals of 0.05 within the range $0-1.0$. The thresholds are labeled at intervals of 0.1 along each curve. ROC curves using both 0.5 and $1.0 \mathrm{~g} \mathrm{~m}^{-3}$ to define high TWC events requiring detection are shown in top and bottom panels, respectively, of Fig. 12. A ROC curve for a perfect PHIWC product would intercept the $(0.0,1.0)$ coordinate and the area under the curve (AUC) would equal 1.0. The PHIWC threshold nearest the $(0.0,1.0)$ coordinate can be considered the optimal thresh- 
old because it yields the best compromise between POD and FAR. Therefore AUC was used as a metric to quantify the skill of the PHIWC product, and the optimal PHIWC threshold was identified based on maximum AUC. For PHIWC day $_{\text {, }}$ (solid black curve) the optimal PHIWC threshold is 0.70 and yields a $75 \%$ POD and $35 \%$ FAR based on the $0.5 \mathrm{~g} \mathrm{~m}^{-3}$ threshold. This is consistent with the flight track time series results where a $\mathrm{PHIWC}_{\text {day }}>0.70$ regularly identified high TWC events. The optimal threshold for PHIWC night $_{\text {(solid }}$ gray curve) is 0.55 and yields a $60 \%$ POD and $32 \%$ FAR.

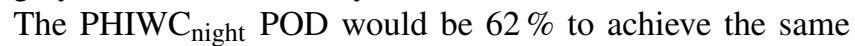

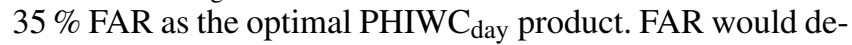
crease by up to $10 \%$ if a lower TWC threshold such as $0.01-$ $0.05 \mathrm{~g} \mathrm{~m}^{-3}$ were used to define cloud because the satelliteobserved characteristics of clouds with such low TWC rarely triggers high PHIWC. But it is felt that $0.1 \mathrm{~g} \mathrm{~m}^{-3}$ provides the most reliable detection of cloud boundaries and that statistics using this threshold are most representative of true product performance, keeping in mind the challenges associated with validation described below.

The reduction of skill for PHIWC $_{\text {night }}$ is not especially surprising given Fig. 6 that showed a relatively wide range of IR-only dOT and $\triangle \mathrm{BTW}$ for TWC $>0.5 \mathrm{~g} \mathrm{~m}^{-3}$. Lower PHIWC $_{\text {night }}$ values on average also reflect this uncertainty. The combination of these IR-based fields with COD and especially VIS texture detection more precisely depicts where HIWC is likely than the IR-based fields alone. In the event that a COD retrieval product is unavailable due to latency constraints, VIS OT and texture can be combined with IR OT detection to derive dOT and an alternative two-parameter PHIWC $_{\text {day }}$ product. Based on TWC $>0.5 \mathrm{~g} \mathrm{~m}^{-3}$, this alternative two-parameter PHIWC day $_{\text {(Fig. 12, dashed black }}$ curve) would provide a $6 \%$ reduction in $\mathrm{POD}$ relative to the three-parameter PHIWC $_{\text {day }}$ but a $7 \%$ improvement over the PHIWC $_{\text {night }}$ for a constant $35 \%$ FAR.

If HIWC conditions are defined as TWC $>1.0 \mathrm{~g} \mathrm{~m}^{-3}$ rather than TWC $>0.5 \mathrm{~g} \mathrm{~m}^{-3}$ the accuracy of PHIWC is affected very little. The maximum AUC changes only slightly for all three PHIWC versions. A higher PHIWC threshold is required to discriminate the $1.0 \mathrm{~g} \mathrm{~m}^{-3} \mathrm{TWC}$ events; for example, the optimal PHIWC day threshold is 0.75 (versus 0.70 for $0.5 \mathrm{~g} \mathrm{~m}^{-3}$ ) which yields a $75 \%$ POD and $37 \%$ FAR.

A comparison of the PHIWC distribution for varying TWC intervals is shown in Fig. 13. In general, both

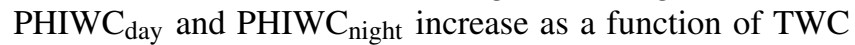
up to a value of $1.0 \mathrm{~g} \mathrm{~m}^{-3}$ but then level off at high PHIWC values in HIWC conditions. Very high TWC $\left(>2 \mathrm{~g} \mathrm{~m}^{-3}\right.$, 95th percentile in this $45 \mathrm{~s}$ dataset) seldom occurs when PHIWC $_{\text {day }}<0.7$ and PHIWC $_{\text {night }}<0.4$ during Florida-2015 and Darwin-2014 campaigns. Cayenne-2015 featured sev-

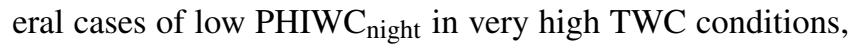
perhaps driven by the coarse 30 min GOES sampling that cannot always capture rapidly evolving OTs or cold cloud tops signifying HIWC conditions. The Cayenne-2015 campaign featured the lowest PHIWC on average due to the (a) TWC threshold $=0.5 \mathrm{~g} \mathrm{~m}^{-3}$

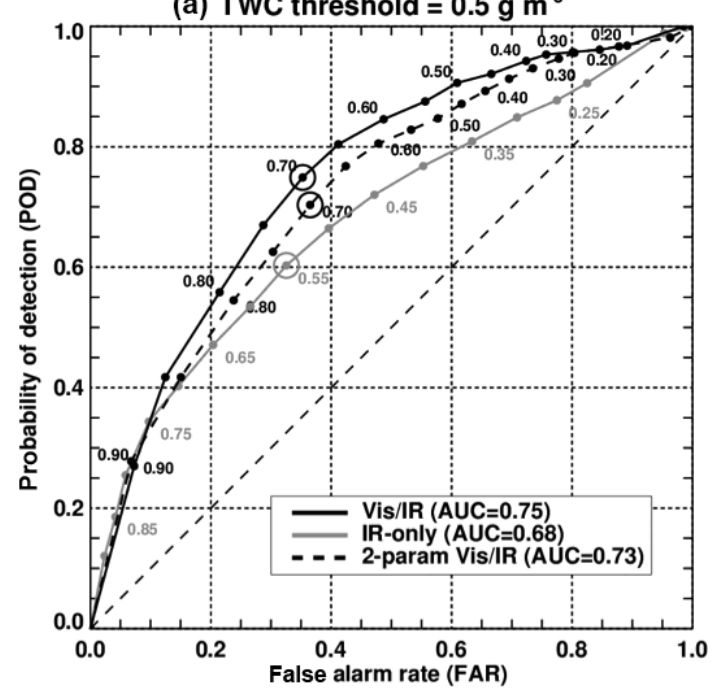

(b) TWC threshold $=1.0 \mathrm{~g} \mathrm{~m}^{-3}$

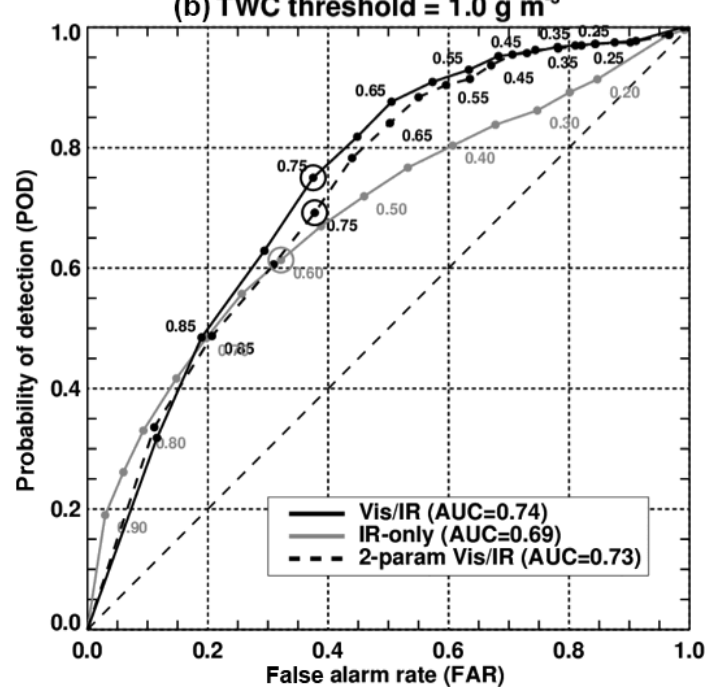

Figure 12. A receiver operating characteristic (ROC) curve showing the relationship between POD and FAR for PHIWC thresholds ranging from 0.0 to 1.0 (labeled at 0.1 increments) based on TWC thresholds of $0.5 \mathrm{~g} \mathrm{~m}^{-3}$ (a) and $1.0 \mathrm{~g} \mathrm{~m}^{-3}$ (b). The solid black curve represents the three-parameter $\mathrm{PHIWC}_{\text {day }}$ and the solid grey curve represents the two-parameter PHIWC $_{\text {night }}$. The dashed black curve represents an algorithm formulation using $\triangle \mathrm{BTW}$ and dOT analogous to PHIWC $\mathrm{C}_{\text {night }}$, but VIS OT and texture detections in addition to IR OT detections are used to derive dOT. This formulation could be used for daytime HIWC detection in the event that a COD retrieval product is unavailable. Optimal PHIWC values based on the maximum area underneath the ROC curve (AUC) are circled and the corresponding AUC is provided in the legend.

fact that clouds had the warmest cloud tops and greatest $\triangle \mathrm{BTW}$. There are many instances of low PHIWC $\mathrm{C}_{\text {ight }}$ but

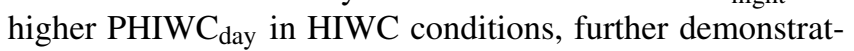
ing the importance of COD and VIS dOT. Challenges associated with PHIWC validation are discussed in the next section 

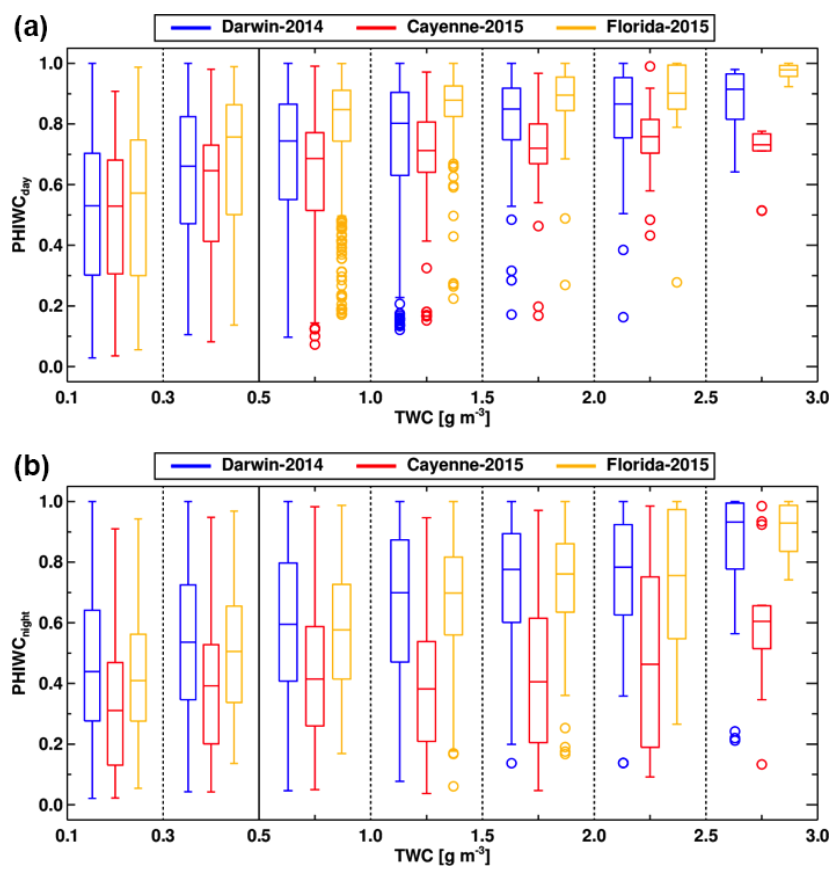

Figure 13. Box and whisker diagrams showing the relationship between PHIWC $_{\text {day }}$ (top, $N=4598$ satellite-aircraft matches), PHIWC $_{\text {night }}$ (bottom, $N=5371$ ) and TWC. The rectangles show the intraquartile PHIWC range for each TWC bin. The horizontal line within the rectangles shows the median PHIWC. The whiskers show the range of the 1.5 and $98.5 \%$ of the distribution and circles are outliers.

that could help to explain perceived deficiencies in the products.

One point to consider when interpreting these results is that $45 \mathrm{~s}$ TWC data was used to develop and validate the TWC algorithms, not the native $5 \mathrm{~s}$ data. Though $45 \mathrm{~s}$ data is more representative of the size of a $2 \times 2$ GEO pixel clusters co-located with the aircraft than $5 \mathrm{~s}$, averaging across the $45 \mathrm{~s}$ window dampens mesoscale variability that could contribute to temperatures and spatial patterns observed by satellite, especially texture in $1 \mathrm{~km}$ VIS imagery that is 16 times finer than $4 \mathrm{~km} \mathrm{IR} \mathrm{BT}$. For example, the PHIWC $\mathrm{C}_{\text {day }}$ threshold of 0.70 featured a $35 \%$ FAR based on $45 \mathrm{~s}$ data. $41 \%$ of these false positives featured a $5 \mathrm{~s}$ TWC $>0.5 \mathrm{~g} \mathrm{~m}^{-3}$ and $1.0 \%$ featured TWC $>1.0 \mathrm{~g} \mathrm{~m}^{-3}$. Of course the true positive rate would almost certainly decrease if, for example, $5 \mathrm{~s}$ TWC $>0.5 \mathrm{~g} \mathrm{~m}^{-3}$ required high PHIWC. Thus, there are both pros and cons regarding the use of 5 versus $45 \mathrm{~s}$ TWC data that complicate validation, but it is felt that the PHIWC algorithm based on $45 \mathrm{~s}$ data is robust.

During the Darwin-2014 and Cayenne-2015 campaigns, the $95 \mathrm{GHz}$ Doppler Radar System Airborne (RASTA, Protat et al., 2009) provided vertical TWC profiles above and below the aircraft that can be used to estimate if false detections from the PHIWC products based on comparison with IKP2 were truly false, namely there were no retrievals of
TWC $\geq 0.5 \mathrm{~g} \mathrm{~m}^{-3}$ anywhere within the column. TWC observed during the flight campaigns decreased with height by $33 \%$ from the $-10^{\circ} \mathrm{C}$ layer to the -30 to $-50^{\circ} \mathrm{C}$ layer. If the aircraft was flying at $-50{ }^{\circ} \mathrm{C}$ and measured $0.4 \mathrm{~g} \mathrm{~m}^{-3}$, TWC could exceed 0.5 or possibly $1.0 \mathrm{~g} \mathrm{~m}^{-3}$ at lower altitudes in the same column. Moderate to high TWC at low to mid-levels could be correlated with cold and/or textured cloud tops that would trigger high PHIWC values. Flightlevel RASTA TWC retrievals were found to have a $\sim 10$ $30 \%$ bias and $40-70 \%$ root-mean-squared difference relative to in situ TWC measurements during the Darwin-2014 campaign (Protat et al., 2016). Although RASTA TWC estimates remote from the aircraft level have not yet been validated for accuracy, the radar TWC retrievals were considered to be adequate to analyze for the following false detections (Protat et al., 2016). A FAR of $31 \%$ was found for 0.7 PHIWC $_{\text {day }}$ for Darwin-2014 and Cayenne-2015 based on a $0.5 \mathrm{~g} \mathrm{~m}^{-3}$ IKP2 threshold. $82 \%$ (35\%) of the false detections were collocated with RASTA column-maximum TWCs that exceeded $0.5(1.0) \mathrm{g} \mathrm{m}^{-3}$ at heights above the freezing level. This suggests that vertical sampling bias, especially when the aircraft flew at higher flight levels where TWC is lower on average, is likely influencing the IKP2-based validation statistics and therefore these statistics may not be truly representative of product performance.

On the other hand, when column-max RASTA TWC is used as truth for Darwin-2014 and Cayenne-2015, a nearly identical shape of the ROC curves relative to those from IKP2 (not shown) was found. When the column-maximum RASTA TWC is analyzed in conjunction with the satellite parameters used to derive PHIWC, very similar relationships are found with those shown in Fig. 6 which would lead to comparable RASTA-based PHIWC. So while some perhaps appreciable fraction of the false detection rate can be explained by vertical variability and sampling bias, use of RASTA data is not enabling significant improvement in overall PHIWC accuracy.

\section{Discussion}

Our analysis found that HIWC conditions are most common during periods of flight within or beneath optically thick cloud tops having temperatures near to or colder than the tropopause and within $40 \mathrm{~km}$ of an OT or textured cloud top. A combination of VIS-based texture detection and COD retrieval helps to pinpoint where HIWC conditions are likely within or beneath a broad area of cold anvil. High COD indicates a cloud top composed of dense ice which generates high VIS reflectance. The $R_{\text {eff }}$ showed a nearly identical distribution in moderate and high TWC conditions, so the high COD and VIS reflectance is driven either by a high ice mixing ratio in anvil clouds without deep convection underneath or by large vertical cloud thickness, i.e., the presence of deep convection. Convective updrafts depicted by OT re- 
gions, high $\mathrm{COD}$, and low $\triangle \mathrm{BTW}$ are where strong ice mass flux occurs and the high TWC is likely be generated. The high TWC is then advected laterally within the anvil. These results are consistent with previous studies such as Grzych et al. (2015) and Bravin et al. (2015) who identified that engine icing events often occurred during long traverses through MCS clouds with cold tops, and in particular near to tops penetrating significantly above the surrounding anvil.

An alternative HIWC diagnostic method from de Laat et al. (2017) identifies any ice phase cloud top with moderate or greater COD $(\geq 20)$ in the form of a binary HIWC mask. The goal of the de Laat et al method was to maximize the critical success index parameter which emphasizes POD. For example, based on a TWC threshold of $0.5 \mathrm{~g} \mathrm{~m}^{-3}$, the de Laat method would have offered a $100 \%$ POD and $96 \%$ FAR using the daytime satellite-aircraft match database from the three campaigns, indicating that this product is more useful for telling users where HIWC conditions cannot be present, rather than where it is present based on satellite-observed cloud conditions. It is unlikely that pilots would avoid an entire anvil simply because it is composed of ice and is at least somewhat optically thick. The approach described in this paper attempts to better discriminate where HIWC is present within a broad area of anvil which is advantageous for tactical HIWC avoidance.

Validation of the PHIWC products using in situ TWC is a challenge and is potentially misleading for a variety of reasons. A primary reason for disagreement between PHIWC and TWC noted throughout this paper is the fact that the method is attempting to infer conditions at flight level from observations of cloud tops. The PHIWC product best represents conditions within the anvil that aircraft would encounter while cruising at levels typically above $9 \mathrm{~km}$ where anvils reside. Consider the situation where an intense lightning-producing convective cell with an OT is producing extremely cold, optically thick, and spatially broad anvil that would generate a large area of high PHIWC. Low to mid-level cloud (flight level -10 to $-30^{\circ} \mathrm{C}$ ) containing low TWC may be present beneath and de-coupled from the anvil above. This low TWC would agree poorly with the high PHIWC. Lightning detection data were used extensively in aircraft flight planning and routing during the campaigns. Active lightning-producing convective cores were intentionally avoided to ensure aircraft safety and preserve the science instrumentation, although the lightning measurements were also used to locate promising active cells for sampling shortly after the lightning had dissipated. In some flights, Flights 5 and 6 (19 and 21 August) in Florida-2015 for example, the aircraft could not sample freely due to the frequent combination of both lightning and high radar reflectivity at flight altitude. In such cases, the measurements were usually made along the edge or at an otherwise safe distance from the intense cell. This resulted in lower measured TWC values than would likely be present inside the cells. In vertically continuous clouds, a general decrease in observed TWC with height also affects the validation statistics. Flight at $-50{ }^{\circ} \mathrm{C}$ may sample TWC below 0.5 or $1.0 \mathrm{~g} \mathrm{~m}^{-3}$ but greater TWCs are likely to be present at lower flight levels in the same column. High PHIWC would be considered a false detection relative to TWC at $-50^{\circ} \mathrm{C}$ scenario but correct at levels below.

The aircraft proximity to an updraft, downwind vs. upwind, may also have an impact on observed TWC and thus our interpretation of satellite-derived data with respect to TWC. It is reasonable to assume that greater TWC would be sampled in new outflow downwind of an updraft versus upwind of the same updraft. New OTs often form in a cirrus shield composed of dissipating remnants from earlier decayed cells. The satellite could then observe cold, optically thick cloud close to and all around an OT region, triggering high PHIWC, but the highest TWC at given altitude would arguably be at a downwind position from the OT. It therefore stands to reason that the winds derived from a numerical weather prediction (NWP) model analysis or forecast could be another useful predictor for PHIWC. Unfortunately, outflow from deep convection can alter the upper tropospheric wind environment. Models often do not simulate convection at exactly the right place and time, and even if a storm were accurately simulated, the model may not correctly simulate the interaction of the synoptic scale winds with the convective outflow. These challenges would complicate the use of the wind field as a PHIWC predictor in an automated product. "Mesoscale atmospheric motion vectors" derived from tracking cloud features embedded within anvils using "rapid scan" geostationary imagery, such as those collected at up to $30 \mathrm{~s}$ intervals by the GOES-R Advanced Baseline Imager (Schmit et al., 2005), could help to identify regions where fresh outflow from updrafts is occurring (Bedka and Mecikalski, 2005; Apke et al., 2016). Use of observed cloud motions would alleviate concerns about incorrect model depictions of the wind field in deep convection. One could envision that flight through fresh outflow in an anvil would be more likely to experience higher TWC. Nevertheless, in an environment with multiple updrafts in close proximity to each other, where the aircraft may be upwind of one updraft by several $\mathrm{km}$ but downwind of another by tens of $\mathrm{km}$, it would be difficult to understand exactly how, and from where, the observed TWC is generated. Unraveling these complex relationships is a topic for future work.

Another point to consider when interpreting these results is that our analysis framework treated each satellite image as an individual snapshot and did not account for the temporal evolution of the clouds nor the distance which a commercial aircraft might traverse in high PHIWC within the cloud. Both of these factors could offer additional value in a PHIWC diagnostic product. Bravin et al. (2015) noted that in-service engine icing events occurred within an hour of the maximum intensity of a local OT region that the aircraft traversed, supporting the use of automated OT detection for identification of HIWC threat. Their analysis was based on a manual analysis of storm system evolution and comparison to engine- 
event aircraft tracks. This may be practical to do with an automated algorithm for large and isolated MCSs observed at high temporal resolution, but it may be very difficult to identify OTs in shorter-lived smaller storms or clusters of storms with anvil mergers. A primary contribution of uncertainty to the analysis of this article is caused by the coarse spatial and temporal resolution of the GOES and MTSAT imagers. These instruments cannot resolve all of the OT signatures that may truly be present in higher spatial resolution imagery such as that from the Moderate Resolution Imaging Spectroradiometer (MODIS) and cannot depict the rapid temporal evolution of BTW and OT within updrafts. Exceptions to this were the two Florida-2015 flights sampled at 1 min intervals by GOES-14. One of these flights shown in Fig. 11 illustrates very good correlation between TWC and the derived PHIWC, suggesting that high temporal resolution imagery would improve our statistics. For example, if an OT had formed shortly after the first of two GOES images 30 min apart, it would not be registered on the first image. High TWC could then be observed by the research aircraft but associated with a low PHIWC value derived from the first image.

Given the reduced PHIWC $_{\text {night }}$ performance relative to PHIWC $_{\text {day }}$, and in general, some error/uncertainty with the PHIWC products, consideration could be given to other parameters such as cloud top temperature and cloud top height available in near real-time that might improve performance. In optically thick deep convection, the IR emissivity is very close or equal to 1 , so the cloud top temperature is equivalent to the observed IR BT and therefore provides no new information. A cloud top height retrieval that properly handles semi-transparent clouds would offer value over IR BT, but this study has shown that high TWC almost never occurs within thin cirrus. Satellite observations in water vapor absorption channels have been used to derive nighttime COD which provide some sensitivity to COD variations in optically thick deep convective clouds (Minnis et al., 2016), much better than what is provided by the SIST algorithm described in Sect. 2.3.2 above which is limited to a COD of approximately eight. The use of these new nighttime COD retrievals will be explored in future PHIWC product versions.

Other data from NWP models such as thermodynamic parameters including total precipitable water (TPW), convective available potential energy (CAPE), or dynamic forcing for convection such as boundary layer convergence, midtropospheric $(500 \mathrm{hPa})$ vorticity, or cloud top divergence, could also be included in a PHIWC product. High TPW is typically present in broad areas of the tropics and would perhaps contribute to a greater concentration of water and ice hydrometeors in deep convection. It is very difficult to understand why high TWC was measured in some clouds and not others nearby in what appears to be same TPW environment based on NWP analyses. Complex mesoscale dynamics such entrainment of cold outflow and/or dry subsiding air from nearby convective cells would likely have a greater impact on storm intensity and its ability to generate HIWC conditions than the TPW of the air mass depicted by a NWP model. The magnitude of CAPE is thought to govern the maximum updraft speed attainable in deep convection. Studies such as Rosenfeld et al. (2008) have suggested that stronger updrafts lead to generation of a greater concentration of small ice particles. Given that previous studies have linked small ice particles to HIWC events, it is possible that there would be a statistical relationship between CAPE and high TWC. Greater CAPE and faster updrafts would furthermore cause stronger ice. Storms typically form along CAPE gradients and the CAPE computation is highly sensitive to the boundary layer moisture and temperature profiles that are very challenging for NWP to correctly simulate. Grzych and Mason (2011) analyzed a subset of nearly 100 engine events, and found that only $12 \%$ of the events occurred in atmospheres with CAPE greater than $2500 \mathrm{~J} \mathrm{~kg}^{-1}$ (strongly unstable). The vast majority of events occurred in moderate or marginally unstable conditions, and thus CAPE did not appear to be a major driver of events. Due to these issues, the direct use of CAPE in a PHIWC product are likely to be problematic and prone to NWP model-dependent biases, and lacking in support for correlation to HIWC encounters. Dynamical fields such as those listed above provide forcing for convection, governing where convection does and does not occur, and also modulating storm intensity especially in the case of boundary layer convergence. Unfortunately, NWP models do not always simulate these often narrow convergence zones in the right place and time which would induce error in the PHIWC product. Satellite observations themselves inform the PHIWC product on where deep convection is present and about locations within the convective cloud where storm dynamics are likely to be strongest. Thus it seems that fields such as vorticity and divergence would not provide any new information, and errors in these fields could adversely impact PHIWC product performance.

Given that the HIWC and HAIC flight campaigns targeted deep convection in large MCSs, primarily in tropical and subtropical regions, the PHIWC product will perform best in identifying icing conditions in such convective cloud environments. The in-service engine icing events described by Mason et al. (2006), Grzych and Mason (2010), Mason and Grzych (2011), Grzych et al. (2015), and Bravin et al. (2015) occurred in deep convective clouds dominated by large MCSs, but smaller scale convective cloud was also noted. Furthermore, ice particle icing events also include air data probe events, for which there is little published information on cloud type. It is therefore prudent to note that the PHIWC product may not be tuned for all clouds that would produce significant ice particle icing events. In order to better understand all types of aircraft icing generated by ice particles, additional data from research aircraft flights through other cloud environments such as smaller scale convective clouds and mid-latitude cyclones would be beneficial. In addition, provision of detailed information from the aviation 
industry to the research community on all types of in-service icing events would benefit nowcasting product development in covering the full spectrum of icing conditions.

\section{Summary}

This paper describes analysis of GEO satellite-derived products relative to in situ TWC observations collected in deep convective clouds by research aircraft during the recent HAIC-HIWC flight campaigns out of Darwin, Australia and Cayenne, French Guiana, and the NASA HIWC-RADAR flight campaign out of Fort Lauderdale, Florida. The intent of this analysis was to determine which satellite-derived products were best for discriminating HIWC conditions depicted by aircraft in situ total water content (TWC) observations toward development of a Probability of HIWC (PHIWC) diagnostic product. Satellite-derived products such as cloud optical depth (COD), $11 \mu \mathrm{m}$ IR window brightness temperatures normalized by the tropopause temperature $(\triangle \mathrm{BTW})$, the distance to the nearest overshooting cloud top detection in IR or VIS imagery, and distance to the nearest textured region detection in VIS imagery (dOT) can be used to effectively discriminate low-to-moderate from high TWC (i.e., HIWC) conditions. Flights through or beneath optically thick anvil cloud within $40 \mathrm{~km}$ of OTs or textured regions were most likely to experience HIWC conditions. In general, discrimination between moderate and high TWC conditions using satellite-derived signals at cloud top was found to be very challenging because (1) satellites observe signals and processes occurring at or near cloud top while the aircraft sampled cloud conditions typically several kilometers below the top and (2) the satellite products appear less sensitive to TWC beyond $0.5 \mathrm{~g} \mathrm{~m}^{-3}$ (the 50th percentile of TWC for this satellite-aircraft matched dataset); in other words the same combination of satellite parameters can be present when either 0.5 or $2.0 \mathrm{~g} \mathrm{~m}^{-3}$ TWC are observed.

PHIWC diagnostic products for both day and night application were developed using a fuzzy logic approach based on statistical fits between satellite data and aircraft TWC observations throughout the three campaigns. Examples from several flights across the three campaigns showed that PHIWC $_{\text {day }}$ generally followed TWC trends throughout the flights, with departures being attributed to (1) the fact that the aircraft often sampled far below the cloud top being observed by satellite and (2) the often coarse temporal and spatial resolution of the satellite imagery that cannot resolve rapidly evolving phenomena such as OT signatures. The PHIWC $\mathrm{C}_{\text {night }}$ was able to identify HIWC conditions only when the aircraft flew through or beneath cold cloud tops near OT regions detected in IR imagery. High TWC occurred in one daytime example during Cayenne-2015 beneath optically thick and textured cloud with IR temperatures $25 \mathrm{~K}$ warmer than the tropopause. In this case, inclusion of the VIS-based information provided some ability to identify
HIWC conditions, where almost no identification would have been possible at night due to the warm cloud tops.

Validation of the PHIWC products employing a subset of the pixel-scale satellite-aircraft matches, using TWC $>0.5 \mathrm{~g} \mathrm{~m}^{-3}$ to define an event, showed a true and false positive rate (i.e., POD and FAR) of 75 and $35 \%$ for PHIWC $_{\text {day }}$ with a ROC AUC of 0.75 . PHIWC night provided a $62 \%$ POD for an equivalent FAR. The POD rises to $69 \%$ in the absence of COD but with inclusion of VIS OT and texture detection in the dOT product. Product performance changed only slightly when TWC $>1.0 \mathrm{~g} \mathrm{~m}^{-3}$ was evaluated. It was found that through the use of TWC vertical profiles retrieved using vertically pointing RASTA cloud radar data on the Falcon 20 aircraft, rather than just in situ data, a substantial fraction of the false positives in the PHIWC $_{\text {day }}$ had some TWC $\geq 0.5 \mathrm{~g} \mathrm{~m}^{-3}$ in the column of air above or below the aircraft, reflecting dynamics and/or microphysics that contributed to the high PHIWC. PHIWC values increased on average in the 0.1 to $1 \mathrm{~g} \mathrm{~m}^{-3}$ TWC range and then leveled off at higher TWC values. Very high TWC $\left(>2 \mathrm{~g} \mathrm{~m}^{-3}\right)$ occurred where the highest PHIWC were identified. PHIWC $\mathrm{C}_{\text {night }}$ for the Cayenne-2015 campaign was significantly lower than the other two campaigns due to the warmer cloud tops in both an absolute and tropopause-relative sense. Interpreting the product validation is quite challenging due to the fact that satellite observations of cloud top are being used to infer in-cloud processes and microphysical distributions, compounded by satellite sampling limitations such as the coarse 30 min GOES-13 resolution available during Cayenne-2015.

It is envisioned that the PHIWC diagnostic products could be used in real-time operations in a tactical sense, at up to a $1 \mathrm{~h}$ lead time, to identify and avoid regions within cloud systems that are likely to generate high TWC. This work demonstrates that the PHIWC products offer improved capability for identifying HIWC conditions in deep convection relative to other known diagnostic products. GEO imager data can now be acquired over a broad (i.e., hemispheric) geographic domain from a remote server and processed with the OT and texture detection algorithms in $\sim 5 \mathrm{~min}$. COD retrievals are more time consuming to produce but inclusion of this product increases accuracy by $8 \%$ if some modest latency is not a concern to users. Rapid data access and processing enables real-time production, even with next-generation satellite imager data such as the GOES-16 Advanced Baseline Imager (ABI, Schmit et al., 2005) and Himawari-8 Advanced Himawari Imager (AHI, Bessho et al., 2016) that feature $4 \times$ higher spatial resolution than GOES-13 or MTSAT and have the capability to view hemispheric domains at $10-15 \mathrm{~min}$ intervals.

Data availability. Satellite imagery and derived products are available from the authors upon request. HAIC-HIWC datasets (Strapp, 2016, b, 2017; SAFIRE and RASTA datasets) are available from the UCAR/NCAR Earth Observing Laboratory at http://data.eol. 
ucar.edu/master_list/?project=HAIC-HIWC but are available solely to core users of the HAIC-HIWC consortium until 14 July 2019. HAIC-HIWC data are available to all other individuals upon signing a data exchange protocol between 15 July 2019 and 14 July 2022. HAIC-HIWC data are fully publicly available on or after 15 July 2022. HIWC-Radar data are currently available upon request and will be available from the UCAR/NCAR Earth Observing Laboratory: https://data.eol.ucar.edu/project/545.

\section{The Supplement related to this article is available online at https://doi.org/10.5194/amt-11-1615-2018-supplement.}

Competing interests. The authors declare that they have no conflict of interest.

Acknowledgements. This work was supported by the Advanced Air Transport Technology Project within the NASA Aeronautics Research Mission Directorate Advanced Air Vehicles Program. Major North American funding for flight campaigns and associated research was provided by provided by the FAA William Hughes Technical Center and Aviation Weather Research Program, the NASA Aeronautics Research Mission Directorate Aviation Safety Program, the Boeing Co., Environment Canada, the National Research Council of Canada, and Transport Canada. Major European campaign and research funding was provided by (i) the European Commission Seventh Framework Program in research, technological development and demonstration under grant agreement no. ACP2-GA-2012-314314; and (ii) the European Aviation Safety Agency (EASA) Research Program under service contract no. EASA.2013.FC27. Further funding was provided by the Ice Crystal Consortium.

We acknowledge the operators of the aircraft that collected the TWC data used in this paper. For the Falcon 20, primary support was provided by the SAFIRE facility for the scientific airborne operations. SAFIRE (http://www.safire.fr), is a joint facility of CNRS, Météo-France and CNES. For the NASA DC-8, primary support was provided by the NASA Armstrong DC-8 crew, including Tim Moes, NASA DC-8 project manager. We thank the following for HIWC and HAIC project management support: Tom Bond, Jim Riley, and Chris Dumont - Federal Aviation Administration; Ron Colantonio - NASA Aerosciences Evaluation \& Test Capabilities Project Manager; Alice Calmels and Fabien Dezitter - Airbus Ind.; Steven Harrah - NASA Langley's radar principal investigator; Peter May and Rod Potts - Australian Bureau of Meteorology; and Jeanne Mason - the Boeing Company. The authors would like to acknowledge the FAA Aviation Research Division, the NASA Aviation Safety Program, and Tom Ratvasky and Steven Harrah from NASA for their leadership and support. We thank the Japan Meteorological Agency (JMA) for their special efforts in providing $10 \mathrm{~min}$ resolution visible and infrared MTSAT-1R satellite data during the Darwin campaign. We also thank the Data Center at the University of Wisconsin Space Science and Engineering Center (SSEC) for providing the archived GEO satellite imagery used in this analysis and SSEC in general for their continued support of the McIDAS software package.

Edited by: Alexander Kokhanovsky

Reviewed by: Adrianus de Laat and two anonymous referees

\section{References}

Ai, Y., Li, J., Shi, W., Schmit, T. J., Cao, C., and Li, W. Deep convective cloud characterizations from both broadband imager and hyperspectral infrared sounder measurements, J. Geophys. Res.-Atmos., 122, 1700-1712, https://doi.org/10.1002/2016JD025408, 2017.

Apke, J. M., Mecikalski, J. R., and Jewett, C. P.: Analysis of mesoscale atmospheric flows above mature deep convection using super rapid scan geostationary satellite data, J. Appl. Meteorol. Clim., 55, 1859-1887, https://doi.org/10.1175/JAMC-D-150253.1, 2016.

Bedka, K., Brunner, J., Dworak, R., Feltz, W., Otkin, J., and Greenwald, T.: Objective satellite-based detection of overshooting tops using infrared window channel brightness temperature gradients, J. Appl. Meteorol. Clim., 49, 181-202, https://doi.org/10.1175/2009JAMC2286.1, 2010.

Bedka, K., Dworak, R., Brunner, J., and Feltz, W.: Validation of satellite-based objective overshooting cloud-top detection methods using CloudSat cloud profiling radar observations, J. Appl. Meteorol. Clim., 51, 1811-1822, https://doi.org/10.1175/JAMCD-11-0131.1, 2012.

Bedka, K. M. and Khlopenkov, K.: A probabilistic multispectral pattern recognition method for detection of overshooting cloud tops using passive satellite imager observations, J. Appl. Meteorol. Clim., 55, 1983-2005, https://doi.org/10.1175/JAMC-D-150249.1, 2016.

Bedka, K. M. and Mecikalski, J. R.: Application of satellite-derived atmospheric motion vectors for estimating mesoscale flows, J. Appl. Meteorol., 44, 1761-1772, https://doi.org/10.1175/JAM2264.1, 2005.

Bessho, K., Date, K., Hayashi, M., Ikeda, A., Imai, T., Inoue, H., Kumagai, Y., Miyakawa, T., Murata, H., Ohno, T., Okuyama, A., Oyama, R., Sasaki, Y., Shimazu, Y., Shimoji, K., Sumida, Y., Suzuki, M., Taniguchi, H., Tsuchiyama, H., Uesawa, D., Yokota, H., and Yoshida, R.: An introduction to Himawari-8/9 - Japan's new-generation geostationary meteorological satellites, J. Meteorol. Soc. Jpn., 94, 151-183, 2016.

Bravin, M., Strapp, J. W., and Mason, J.: An investigation into location and convective lifecycle trends in an ice crystal icing engine database, Tech. rep., SAE Technical Paper 201501-2130, SAE International, Warrendale, Pennsylvania, USA, https://doi.org/10.4271/2015-01-2130, 2015.

Davison, C. R., MacLeod, J. D., Strapp, J. W., and Buttsworth, D. R.: Isokinetic Total Water Content Probe in a naturally aspirating configuration: Initial aerodynamic design and testing, 46th AIAA Aerospace Sciences Meeting and Exhibit, Reno, Nevada, AIAA2008-0435, 2008.

Davison, C. R., Landreville, C., and MacLeod, J. D.: Initial development and testing of isokinetic probe to measure total water content during ground and airborne testing, NRC, LTR-GTL-20100002, Ottawa, 2010. 
Davison, C. R., Strapp, J. W., Lilie, L., Ratvasky, T. P., and Dumont, C.: Isokinetic TWC evaporator probe: Calculations and systemic error analysis, 8th AIAA Atmospheric and Space Environments Conference, Washington, DC, AIAA-4060, https://doi.org/10.2514/6.2016-4060, 2016.

Dezitter, F., Grandin, A., Brenguier, J.-L., Hervy, F., Schlager, H., Villedieu, P., and Zalamansky, G.: HAIC - High Altitude Ice Crystals, 5th AIAA Atmospheric and Space Environments Conference, American Institute of Aeronautics and Astronautics, available at: http://arc.aiaa.org/doi/abs/10.2514/6. 2013-2674 (last access: 9 February 2015), 2013.

de Laat, A., Defer, E., Delanoë, J., Dezitter, F., Gounou, A., Grandin, A., Guignard, A., Meirink, J. F., Moisselin, J.M., and Parol, F.: Analysis of geostationary satellite-derived cloud parameters associated with environments with high ice water content, Atmos. Meas. Tech., 10, 1359-1371, https://doi.org/10.5194/amt-10-1359-2017, 2017.

Duviver, E.: High Altitude Icing Environment, Intl. Air Safety and Climate Change Conf., 8-9 September 2010, Cologne, Germany, available at: https://www.easa.europa.eu/conferences/ iascc/doc/Workshop1Presentations/Workshop1_DAY2/1_

Duvivier_EASA/IASCC_EDuvivier.pdf (last access: 15 March 2018), 2010.

Gayet, J.-F., Mioche, G., Bugliaro, L., Protat, A., Minikin, A., Wirth, M., Dörnbrack, A., Shcherbakov, V., Mayer, B., Garnier, A., and Gourbeyre, C.: On the observation of unusual high concentration of small chain-like aggregate ice crystals and large ice water contents near the top of a deep convective cloud during the CIRCLE-2 experiment, Atmos. Chem. Phys., 12, 727-744, https://doi.org/10.5194/acp-12-727-2012, 2012.

Grandin, A., Merle, J.-M., Weber, M., Strapp, J. W., Protat, A., and King, P.: AIRBUS flight tests in high ice water content regions, Proceedings of the 6th AIAA Atmospheric and Space Environments Conference, Atlanta, GA, 16-20 June 2014, American Institute of Aeronautics and Astronautics, https://doi.org/10.2514/6.2014-2753, 2014.

Griffin, S., Bedka, K. M., and Velden, C.: A method for calculating the height of overshooting convective cloud tops using satellite-based IR imager and CloudSat Cloud Profiling Radar observations, J. Appl. Meteorol. Clim., 55, 479-491, https://doi.org/10.1175/JAMC-D-15-0170.1, 2016.

Gryzch, M. and Mason, J.: Weather conditions associated with jet engine power loss and damage due to ingestion of ice particles: What we've learned through 2009, 14th Conference on Aviation, Range and Aerospace Meteorology, AMS, Atlanta, GA, 17-21 January 2010.

Grzych, M., Tritz, T., Mason, J., Bravin, M., and Sharpsten, A.: Studies of cloud characteristics related to jet engine ice crystal icing utilizing infrared satellite imagery, SAE Technical Paper 2015-01-2086, https://doi.org/10.4271/2015-01-2086, 2015.

Hong, G., Yang, P., Huang, H. L., Baum, B. A., Hu, Y. X., and Platnick, S.: The sensitivity of ice cloud optical and microphysical passive satellite retrievals to cloud geometrical thickness, IEEE T. Geosci. Remote, 45, 1315-1323, 2007.

Lawson, R. P., Angus, L. J., and Heymsfield, A. J.: Cloud particle measurements in thunderstorm anvils and possible weather threat to aviation, J. Aircraft, 35, 113-121, 1998.

Lazzara, M. A., Benson, J. M., Fox, R. J., Laitsch, D. J., Rueden, J. P., Santek, D. A., Wade, D. M., Whittaker, T. M., and Young, J.
T.: The Man computer Interactive Data Access System: 25 years of interactive processing, B. Am. Meteorol. Soc., 80, 271-284, 1999.

Machado, L. A. T., Lima, W. F., Pinto Jr., O., and Morales, C.: Relationship between cloud-to-ground discharge and penetrative clouds: A multi-channel satellite application, Atmos. Res., 93, 304-309, 2009.

Mason, J. and Grzych, M.: The challenges identifying weather associated with jet engine ice crystal icing, SAE Technical Paper 2011-38-0094, https://doi.org/10.4271/2011-38-0094, 2011.

Mason, J. G., Strapp, J. W., and Chow, P.: The ice particle threat to engines in flight, in: 44th AIAA Aerospace Sciences Meeting, Reno, Nevada, abstract number AIAA 2006-206, 9-12 January 2006.

Martin, D. W., Kohrs, R. A., Mosher, F. R., Medaglia, C. M., and Adamo, C.: Over-ocean validation of the Global Convective Diagnostic, J. Appl. Meteorol. Clim., 47, 525-543, 2008.

Mazzawy, R. and Strapp, J.: Appendix D - An interim icing envelope, SAE Technical Paper 2007-01-3311, https://doi.org/10.4271/2007-01-3311, 2007.

Minnis, P., Nguyen, L., Palikonda, R., Heck., P. W., Spangenberg, D. A., Doelling, D. R., Ayers, J. K., Smith Jr., W. L., Khaiyer, M. M., Trepte, Q. Z., Avey, L. A., Chang, F.-L., Yost, C. R., Chee, T. L., and Sun-Mack, S.: Near-real time cloud retrievals from operational and research meteorological satellites, Proc. SPIE Remote Sensing, Cardiff, Wales, UK, 15-18 September, 7107, https://doi.org/10.1117/12.800344, 2008a.

Minnis, P., Trepte, Q. Z., Sun-Mack, S., Chen, Y., Doelling, D. R., Young, D. F., Spangenberg, D. A., Miller, W. F., Wielicki, B. A., Brown, R. R., Gibson, S. C., and Geier, E. B.: Cloud detection in nonpolar regions for CERES using TRMM VIRS and Terra and Aqua MODIS data, IEEE T. Geosci. Remote, 46, 3857-3884, https://doi.org/10.1109/TGRS.2008.2001351, 2008b.

Minnis, P., Sun-Mack, S., Young, D. F., Heck, P. W., Garber, D. P., Chen, Y., Spangenberg, D. A., Arduini, R. F., Trepte, Q. Z., Smith Jr., W. L., Ayers, J. K., Gibson, S. C., Miller, W. F., Chakrapani, V., Takano, Y., Liou, K. N., and Xie, Y.: CERES Edition-2 cloud property retrievals using TRMM VIRS and Terra and Aqua MODIS data, Part I: Algorithms, IEEE T. Geosci. Remote, 49, 4374-4400, 2011.

Minnis, P., Hong, G., Sun-Mack, S., Smith Jr., W. L., Chen, Y., and Miller, S. D.: Estimating nocturnal opaque ice cloud optical depth from MODIS multispectral infrared radiances using a neural network method, J. Geophys. Res.-Atmos., 121, 4907-4932, https://doi.org/10.1002/2015JD024456, 2016.

Platt, C. M. R., Vaughan, M. A., and Austin, R. T.: Characteristics of CALIPSO and CloudSat backscatter at the top center layers of mesoscale convective systems and relation to cloud microphysics, J. Appl. Meteorol. Clim., 50, 368-378, 2011.

Protat, A., Bouniol, D., Delanoe, J., May, P. T., Plana-Fattori, A., Hasson, A., O'Connor, E., Gorsdorf, U., and Heymsfield, A. J.: Assessment of Cloudsat reflectivity measurements and ice cloud properties using ground-based and airborne cloud radar observations, J. Atmos. Ocean. Tech., 26, 1717-1741, https://doi.org/10.1175/2009JTECHA1246.1, 2009.

Protat, A., Pelon, J., Grand, N., Delville, P., Laborie, P., Vinson, J.-P., Bouniol, D., Bruneau, D., Chepfer, H., Delanoë, J., Haeffelin, M., Noël, V., and Tinel, C.: Le projet RALI: Combinaison 
d'un radar nuage et d'un lidar pour l'étude des nuages faiblement precipitants, La Météorologie, 8e série, 47, 23-33, 2004.

Protat, A., Delanoë, J., Strapp, J. W., Fontaine, E., Leroy, D., Schwarzenboeck, A., Lilie, L., Davison, C., Dezitter, F., Grandin, A., and Weber, M.: The measured relationship between ice water content and cloud radar reflectivity in tropical convective clouds, J. Appl. Meteorol. Clim., 55, 1707-1729, https://doi.org/10.1175/JAMC-D-15-0248.1, 2016.

Rienecker, M. M., Suarez, M. J., Gelaro, R., Todling, R., Bacmeister, J., Liu, E., Bosilovich, M. G., Schubert, S. D., Takacs, L., Kim, G.-K., Bloom, S., Chen, J., Collins, D., Conaty, A., da Silva, A., Gu, W., Joiner, J., Koster, R. D., Lucchesi, R., Molod, A., Owens, T., Pawson, S., Pegion, P., Redder, C. R., Reichle, R., Robertson, F. R., Ruddick, A. G., Sienkiewicz, M., and Woollen, J.: MERRA: NASA's Modern-Era Retrospective Analysis for Research and Applications, J. Climate, 24, 3624-3648, https://doi.org/10.1175/JCLI-D-11-00015.1, 2011.

Rosenfeld, D., Woodley, W. L., Lerner, A., Kelman, G., and Lindsey, D. T.: Satellite detection of severe convective storms by their retrieved vertical profiles of cloud particle effective radius and thermodynamic phase, J. Geophys. Res., 113, D04208, https://doi.org/10.1029/2007JD008600, 2008.

Rugg, A., Haggerty, J., McCabe, G., Palikonda, R., and Potts, R.: High ice water content conditions around Darwin: Frequency of occurrence and duration as estimated by a nowcasting model, 9th AIAA Atmosphere and Space Environment Conference, Denver, CO, USA, 5-9 June 2017.

Sandmael, T. N., Homeyer, C. R., Bedka, K. M., Apke, J. M., Mecikalski, J. R., and Khlopenkov, K.: Using remotely sensed updraft characteristics to discriminate between tornadic and nontornadic storms, submitted, J. Appl. Meteorol. Clim., 2018.

Schmetz, J., Tjemkes, S. A., Gube, M., and van de Berg, L.: Monitoring deep convection and convective overshooting with METEOSAT, Adv. Space. Res., 19, 433-441, 1997.

Schmit, T. J., Gunshor, M. M., Menzel, W. P., Gurka, J. J, Li, J., and Bachmeier, A. S.: Introducing the next-generation Advanced Baseline Imager on GOES-R, B. Am. Meteorol. Soc., 86, 10791096, https://doi.org/10.1175/BAMS-86-8-1079, 2005.

Schmit, T. J., Goodman, S. J., Lindsey, D. T., Rabin, R. M., Bedka, K. M., Cinteneo, J. L., Velden, C. S., Bachmeier, A. S., Lindstrom, S. S., Gunshor, M. M., and Schmidt C. C.: GOES-14 super rapid scan operations to prepare for GOES-R, J. Appl. Remote. Sens., 7, 073462, https://doi.org/10.1117/1.JRS.7.073462, 2014.

Setvak, M., Bedka, K., Lindsey, D. T., Sokol, A., Charvat, Z., St'astka, J., and Wang, P. K.: A-Train observations of deep convective storm tops, Atmos. Res., 123, 229-248, 2013.
Strapp, J. W., MacLeod, J., and Lillie, L. E.: Calibration of ice water content in a wind tunnel/engine test cell facility, 15th Intl. Conf. on Cloud and Precipitation, Cancun, Mexico, 7-11 July, P13.1, 2008.

Strapp, J. W., Korolev, A., Ratvasky, T., Potts, R., Protat, A., May, P., Ackerman, A., Fridlind, A., Minnis, P., Haggerty, J., Riley, J., Lillie, L. E., and Isaac, G. A: The High Ice Water Content study of deep convective clouds: Report on science and technical plan, FAA Rep. DOT/FAA/TC-14/31, 105 pp., available at: http://www.tc.faa.gov/its/worldpac/techrpt/tc14-31.pdf (last access: 14 March 2018), 2016a.

Strapp, J. W., Lilie, L. E., Ratvasky, T. P., Davison, C. R., and Dumont, C.: Isokinetic TWC evaporator probe: Development of the IKP2 and performance testing for the HAIC-HIWC Darwin 2014 and Cayenne 2015 field campaigns, 8th AIAA Atmospheric and Space Environments Conference, AIAA Aviation, AIAA 20164059, https://doi.org/10.2514/6.2016-4059, 2016b.

Strapp, W.: French Falcon Isokinetic Evaporator Probe (IKP2) Data, Version 5.0, UCAR/NCAR - Earth Observing Laboratory, https://doi.org/10.5065/D6WW7GDS, 2016a.

Strapp, W.: French Falcon Isokinetic Evaporator Probe (IKP2) Data, Version 5.0, UCAR/NCAR - Earth Observing Laboratory, https://doi.org/10.5065/D61N7ZV7, 2016b.

Strapp, W.: Ice water content from the isokinetic probe, Version 1.0, UCAR/NCAR - Earth Observing Laboratory, https://doi.org/10.5065/D6RN36KJ, 2017.

Takahashi, H. and Luo, Z.: Where is the level of neutral buoyancy for deep convection?, Geophys. Res. Lett., 39, L15809, https://doi.org/10.1029/2012GL052638, 2012.

World Meteorological Organization: Meteorology - a threedimensional science: Second session of the commission for aerology, World Meteorol. Organ. Bull., 4, 134-138, 1957.

Yang, P., Kattawar, G. W., Hong, G., Minnis, P., and Hu, Y. X.: Uncertainties associated with the surface texture of ice particles in satellite-based retrieval of cirrus clouds: Part II. Effect of particle surface roughness on retrieved cloud optical thickness and effective particle size, IEEE T. Geosci. Remote, 46, 1948-1957, https://doi.org/10.1109/TGRS.2008.916472, 2008.

Young, A. H., Bates, J. J., and Curry, J. A.: Complementary use of passive and active remote sensing for detection of penetrating convection from CloudSat, CALIPSO, and Aqua MODIS, J. Geophys. Res., 117, D13205, https://doi.org/10.1029/2011JD016749, 2012. 